\title{
Global climate response to anthropogenic aerosol indirect effects: Present day and year 2100
}

\author{
Wei-Ting Chen, ${ }^{1,2}$ Athanasios Nenes, ${ }^{3}$ Hong Liao, ${ }^{4}$ Peter J. Adams, ${ }^{5}$ Jui-Lin F. Li, ${ }^{1,2}$ \\ and John H. Seinfeld ${ }^{6}$ \\ Received 12 December 2008; revised 6 January 2010; accepted 7 January 2010; published 26 June 2010.
}

[1] Aerosol indirect effects (AIE) are a principal source of uncertainty in future climate predictions. The present study investigates the equilibrium response of the climate system to present-day and future AIE using the general circulation model (GCM), Goddard Institute for Space Studies (GISS) III. A diagnostic formulation correlating cloud droplet number concentration $\left(N_{c}\right)$ with concentrations of aerosol soluble ions is developed as a basis for the calculation. Explicit dependence on $N_{c}$ is introduced in the treatments of liquid-phase stratiform clouds in GISS III. The model is able to reproduce the general patterns of present-day cloud frequency, droplet size, and radiative balance observed by CloudSat, Moderate Resolution Imaging Spectroradiometer, and Earth Radiation Budget Experiment. For perturbations of $N_{c}$ from preindustrial to present day, a net AIE forcing of $-1.67 \mathrm{~W} \mathrm{~m}^{-2}$ is estimated, with a global mean surface cooling of $1.12 \mathrm{~K}$, precipitation reduction of $3.36 \%$, a southward shift of the Intertropical Convergence Zone, and a hydrological sensitivity of $+3.00 \% \mathrm{~K}^{-1}$. For estimated perturbations of $N_{c}$ from present day to year 2100, a net AIE forcing of $-0.58 \mathrm{~W} \mathrm{~m}^{-2}$, a surface cooling of $0.47 \mathrm{~K}$, and a decrease in precipitation of $1.7 \%$ are predicted. Sensitivity calculations show that the assumption of a background minimum $N_{c}$ value has more significant effects on AIE forcing in the future than on that in present day. When AIE-related processes are included in the GCM, a decrease in stratiform precipitation is predicted over future greenhouse gas (GHG)-induced warming scenario, as opposed to the predicted increase when only GHG and aerosol direct effects are considered.

Citation: Chen, W.-T., A. Nenes, H. Liao, P. J. Adams, J.-L. F. Li, and J. H. Seinfeld (2010), Global climate response to anthropogenic aerosol indirect effects: Present day and year 2100, J. Geophys. Res., 115, D12207, doi:10.1029/2008JD011619.

\section{Introduction}

[2] Aerosols alter the energy balance of the Earthatmosphere system directly by scattering and absorbing sunlight (aerosol direct effect (ADE)), and indirectly by affecting the reflectivity, lifetime, and precipitation formation of clouds. The so-called aerosol indirect effect (AIE), the modification of cloud optical properties (cloud albedo

\footnotetext{
${ }^{1}$ Department of Environmental Science and Engineering, California Institute of Technology, Pasadena, California, USA.

${ }^{2}$ Now at Jet Propulsion Laboratory, California Institute of Technology, Pasadena, California, USA.

${ }^{3}$ Schools of Earth and Atmospheric Sciences and Chemical and Biomolecular Engineering, Georgia Institute of Technology, Atlanta, Georgia, USA.

${ }^{4}$ LAPC, Institute of Atmospheric Physics, Chinese Academy of Sciences, Beijing, China.

${ }^{5}$ Departments of Civil and Environmental Engineering and Engineering and Public Policy, Carnegie Mellon University, Pittsburgh, Pennsylvania, USA.

${ }^{6}$ Departments of Environmental Science and Engineering and Chemical Engineering, California Institute of Technology, Pasadena, California, USA.

Copyright 2010 by the American Geophysical Union. 0148-0227/10/2008JD011619
}

effect), structure, and precipitation (cloud lifetime effect) by aerosols, is judged to be the most uncertain radiative forcing in the climate system [Forster et al., 2007]. General circulation models (GCMs) with explicit aerosol-cloud interactions are the principal tool for estimating the radiative forcing and climatic impacts of the AIE. Current GCM-based estimation of AIE radiative forcing from preindustrial to present day for the cloud albedo effect range from -0.22 to $-1.85 \mathrm{~W} \mathrm{~m}^{-2}$; when changes in cloud lifetime and other feedbacks (e.g., glaciation indirect effects and thermodynamic effects) are included, the values vary from -0.29 to $-2.41 \mathrm{~W} \mathrm{~m}^{-2}$ [Forster et al., 2007].

[3] Climatic impacts of the present-day AIE, relative to preindustrial conditions, have been investigated in GCM studies [Rotstayn et al., 2000; Williams et al., 2001; Rotstayn and Lohmann, 2002; Kristjánsson et al., 2005; Ming et al., 2005; Kirkevåg et al., 2008a, 2008b; Koch et al., 2009]. In these studies the atmosphere is coupled to a slab ocean with interactive sea surface temperature (SST) and fixed heat transport. A qualitatively similar pattern in climate responses was found in these studies: cooling at Northern Hemisphere high latitudes and a southward displacement of the Intertropical Convergence Zone (ITCZ). 


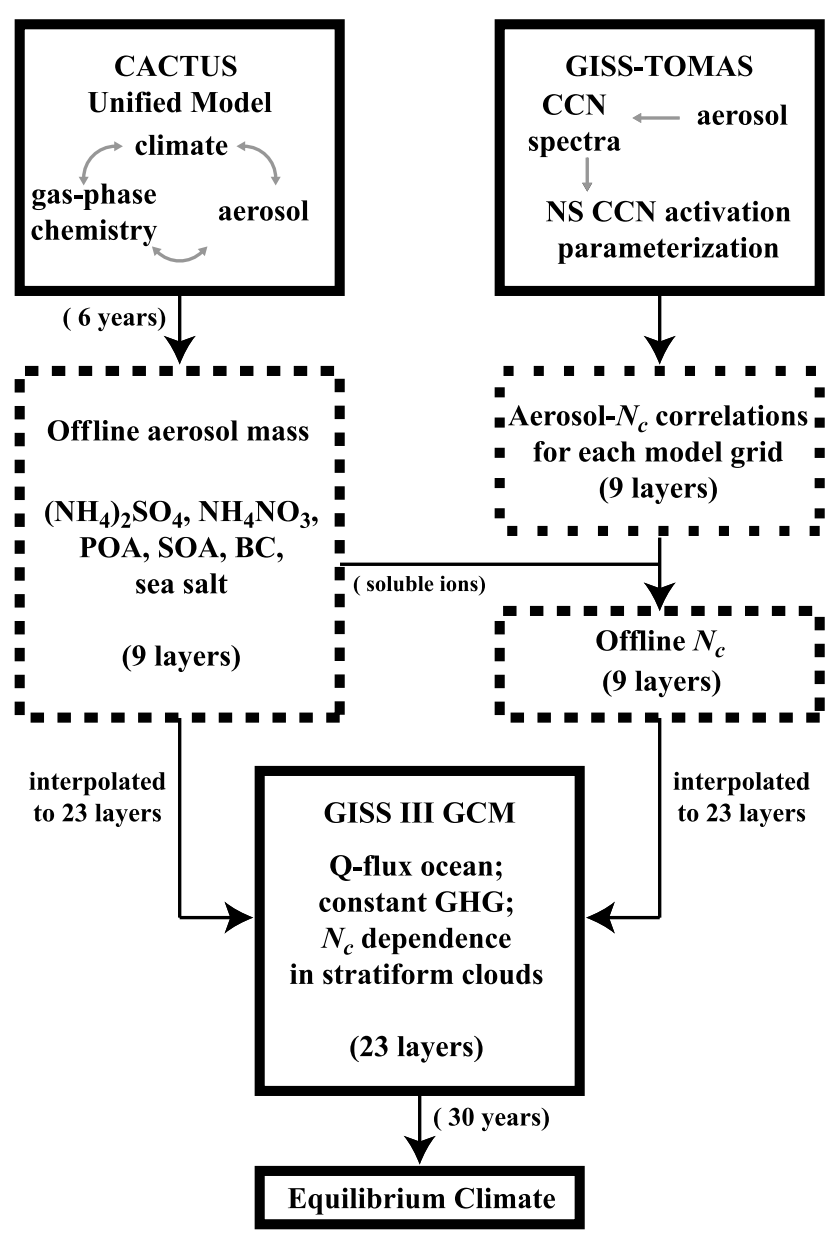

Figure 1. Schematic diagram for experimental design.

Amplified cooling at northern high latitudes associated with sea ice and snow albedo feedbacks was identified by Williams et al. [2001] and Kristjánsson et al. [2005]. In studies exploring the combined impacts of present-day aerosol direct and indirect effects [Feichter et al., 2004; Kristjánsson et al., 2005; Takemura et al., 2005; Kirkevåg et al., 2008a, 2008b; Koch et al., 2009], a weakening of the hydrological cycle over northern high latitudes and a similar southward shift of ITCZ was diagnosed. Combining the direct and indirect aerosol climatic effects with greenhouse gas (GHG) forcing, Feichter et al. [2004] identified a significant nonlinearity in the response of the hydrological cycle using the ECHAM4 model with interactive sulfur chemistry and primary carbonaceous aerosols, and online cloud droplet activation. However, in a similar study using the CCM-Oslo (based on the NCAR Community Climate Model CCM3) with online sulfate and black carbon and lookup tables for CCN activation, Kirkevåg et al. [2008a] found the climatic responses to aerosols and GHG are nearly additive.

[4] In the present work, climate responses to the AIE are studied, with emphasis on changes in the hydrological cycle. We address the following questions: (1) How is climate affected by the anthropogenic perturbations of cloud droplet number concentration $\left(N_{c}\right)$ alone from preindustrial to present day (year 2000), and from present day to future (year 2100)? (2) How is future climate predicted to be influenced by the combined perturbations of anthropogenic GHG, aerosols, and $N_{c}$ ?

[5] Here we use equilibrium climate simulations to investigate the above questions. The simulations are performed using the Goddard Institute for Space Studies (GISS) Global Climate Middle Atmosphere Model III (referred to as GISS III hereafter) coupled to a slab (Q-flux) ocean model. Modifications are made to the formulations of optical depth and autoconversion rates in liquid-phase stratiform clouds in GISS III to introduce explicit dependence on grid-by-grid offline $N_{c}$ fields. In each of the simulations, specific levels of offline monthly averaged aerosol mass concentrations and $N_{c}$ values are input, and the atmospheric dynamics, hydrological cycle, and temperature are allowed to respond accordingly. The corresponding aerosol indirect radiative forcing is calculated, and changes in cloud properties, temperature, precipitation, and circulation between the equilibrium climates are diagnosed. Note that the aerosol indirect effects on stratiform ice clouds and convective clouds are not included in the present study.

[6] A key ingredient in representing the AIE in GCMs is the relation of changes in aerosol amount and properties to changes in $N_{c}$ and cloud droplet size distribution. In the empirical diagnostic approach, $N_{c}$ is formulated as a function of aerosol mass or number concentration, based on ambient data [e.g., Boucher and Lohmann, 1995; Ghan et al., 1997; Menon et al., 2002; Dufresne et al., 2005; Ming et al., 2005; Quaas and Boucher, 2005]. In the prognostic approach, the cloud droplet distribution is predicted based on cloud microphysics [e.g., Kristjánsson et al., 2005; Takemura et al., 2005; Lohmann et al., 2007]. While the earliest studies of the AIE employed the empirical diagnostic approach, the tendency in recent work is to adopt a prognostic microphysics approach to predict cloud droplet properties online and interactively. In the present study, we establish a new, physically based, computationally efficient formulation to relate aerosols and cloud properties diagnostically, allowing for geographical and seasonal variations of aerosol-cloud interactions.

[7] In section 2, a description of the diagnostic aerosolcloud formulation is provided, together with the derivations of offline aerosol mass concentrations and offline $N_{c}$ values, as well as the modifications to the cloud scheme in the GISS III GCM. The associated forcing for perturbations of GHG and aerosols direct and indirect effects is reported in section 3 . Experimental design of the equilibrium climate simulations is outlined in section 4, with the results of the simulations analyzed and discussed in section 5 .

\section{Descriptions of Global Models}

[8] Three different global models were used in this study: the Unified Model developed in the National Aeronautics and Space Administration (NASA) project "Chemistry, Aerosols, and Climate: Tropospheric Unified Simulation" (termed the "CACTUS Unified Model" hereafter), the TwoMoment Aerosol Sectional microphysics model within Goddard Institute for Space Studies (GISS) GCM II' (GISSTOMAS hereafter), and the GISS III GCM. Table 1 summarizes the characteristics of each model, its usage here, and 
Table 1. Global Models in This Study ${ }^{\mathrm{a}}$

\begin{tabular}{|c|c|c|c|c|c|c|}
\hline Model & $\begin{array}{l}\text { Horizontal } \\
\text { Resolution }\end{array}$ & $\sigma$-Layers & $\begin{array}{l}\text { Model } \\
\text { Top (hPa) }\end{array}$ & Feature & $\begin{array}{l}\text { Simulations Performed } \\
\text { in This Study }\end{array}$ & Reference \\
\hline $\begin{array}{l}\text { CACTUS unified } \\
\text { model }\end{array}$ & $4^{\circ}$ Lat by $5^{\circ}$ Lon & 9 & 10 & $\begin{array}{l}\text { Fully coupled chemistry-aerosol- } \\
\text { climate simulations }\end{array}$ & $\begin{array}{l}\text { Derivation of offline } \\
\text { aerosol concentrations }\end{array}$ & $\begin{array}{l}\text { Liao et al. }[2003,2004] \text { and } \\
\text { Liao and Seinfeld }[2005]\end{array}$ \\
\hline GISS-TOMAS & $4^{\circ}$ Lat by $5^{\circ}$ Lon & 9 & 10 & $\begin{array}{l}\text { Size-resolved aerosol and } \\
\text { CCN concentrations }\end{array}$ & $\begin{array}{l}\text { Calculation of CCN } \\
\text { spectra for deriving } N_{c} \\
\text { aerosol correlations }\end{array}$ & $\begin{array}{l}\text { Adams and Seinfeld, } \\
\text { [2002] and Pierce and } \\
\text { Adams }[2006]\end{array}$ \\
\hline GISS III & $4^{\circ}$ Lat by $5^{\circ}$ Lon & 23 & 0.002 & $\begin{array}{l}\text { Cloud scheme modified to include } \\
\text { first and second AIE }\end{array}$ & $\begin{array}{l}\text { Equilibrium climate } \\
\text { simulation }\end{array}$ & Rind et al. [2007] \\
\hline
\end{tabular}

${ }^{a}$ AIE, Aerosol indirect effects; GISS, Goddard Institute for Space Studies; CCN, cloud condensation nuclei.

relevant references. Figure 1 is a flowchart of the simulations in this study, and the steps in which each model is involved. First, the CACTUS Unified Model is used, with fully coupled simulations of tropospheric chemistry, aerosols, and climate, to calculate an annual cycle of monthly averaged aerosol mass concentrations for preindustrial (PI, roughly corresponding to the year 1800), year 2000 (20C), and year 2100 (21C). Next, grid-by-grid correlation formulations between $N_{c}$ and aerosol soluble ions are developed using GISS-TOMAS and the sectional cloud condensation nuclei (CCN) activation parameterization of Nenes and Seinfeld [2003] (hereafter NS) with the droplet growth kinetic modifications of Fountoukis and Nenes [2005] (hereafter FN). With this formulation and the aerosol mass concentrations from the CACTUS Unified Model, offline, monthly averaged values of $N_{c}$ for PI, 20C, and $21 \mathrm{C}$ are calculated. Finally, optical depth and autoconversion rates in the liquid-phase stratiform cloud scheme of GISS III are adjusted to include explicit dependence on $N_{c}$. A set of equilibrium climate simulations was carried out, each with specific levels of GHG, offline aerosol mass, and offline $N_{c}$. The differences between the equilibrium simulations were analyzed to identify the impacts of AIE on the hydrological cycle and future climate changes.

\subsection{CACTUS Unified Model and Offline Aerosol Mass Concentration}

[9] The CACTUS Unified Model, based on the $4^{\circ}$-latitudeby- $5^{\circ}$-longitude, 9 layer GISS GCM II', simulates the fully coupled interactions of chemistry, aerosol, and climate [Liao et al., 2003; 2004; Liao and Seinfeld, 2005]. The model is coupled to a Q-flux ocean, with monthly horizontal heat transport fluxes taken from Mickley et al. [2004]. Changes in the sea surface temperature and sea ice are determined by energy exchange with the atmosphere, ocean heat transport, and the ocean mixed layer heat capacity [Hansen et al.,
1984; Russell et al., 1985]. The model includes detailed tropospheric $\mathrm{O}_{3}-\mathrm{NO}_{\mathrm{x}}$-hydrocarbon chemistry, as well as heterogeneous processes, such as hydrolysis of $\mathrm{N}_{2} \mathrm{O}_{5}$ and irreversible absorption of $\mathrm{NO}_{3}, \mathrm{NO}_{2}$, and $\mathrm{HO}_{2}$ on wetted particle surfaces. Aerosol species predicted in the model include sulfate, nitrate, ammonium, black carbon (BC), primary (POA) and secondary organic aerosol (SOA), sea salt, and mineral dust. Condensation and dry and wet deposition (not size-dependent) are included in determining the aerosol mass budgets. The CACTUS Unified Model has been used in a number of climate studies to identify the influence of climate change on the predictions of tropospheric chemistry and aerosol [Liao et al., 2006], the climatic impact of ADE [Chen et al., 2007], and the differences between fully coupled and offline chemistry-aerosol-climate simulations [Liao et al., 2009].

[10] In the version of the CACTUS Unified Model used here, the formation of SOA from monoterpenes is based on experimentally determined yield parameters [Griffin et al., 1999a, 1999b; Chung and Seinfeld, 2002], assuming equilibrium partitioning; SOA formation from isoprene is not included in the current version of the model, which will be updated in future work. The aerosol semidirect effect on clouds (i.e., through changes in the atmospheric temperature structure caused by aerosol absorption), in-cloud chemistry, and wet removal of aerosols are accounted for. The model does not include the climatic impact of AIE on the prediction of aerosol fields. On the basis of the calculations given by Liao et al. [2006], a $10 \%$ increase in global mean precipitation results in a $9-13 \%$ decrease in burdens of tracer-like aerosols (e.g., BC and POA). Since the global precipitation change owing to AIE is generally less than $2 \%$, as shown later in the climate simulations, the effects of neglecting AIE-induced climate change on global mean predicted aerosol mass in the present study should be small, but we note that some regional biases may exist.

Table 2. Global Annual Burdens of Aerosols Derived by the CACTUS Unified Model ${ }^{\mathrm{a}}$

\begin{tabular}{|c|c|c|c|c|c|c|c|c|c|}
\hline & \multicolumn{3}{|c|}{ PI } & \multicolumn{3}{|c|}{ Year $2000(20 \mathrm{C})$} & \multicolumn{3}{|c|}{ Year $2100(21 \mathrm{C})$} \\
\hline & Global & $\mathrm{NH}$ & SH & Global & $\mathrm{NH}$ & $\mathrm{SH}$ & Global & $\mathrm{NH}$ & $\mathrm{SH}$ \\
\hline Ammonium bisulfate & 0.41 & 0.19 & 0.22 & 2.87 & 2.27 & 0.60 & 2.74 & 2.01 & 0.73 \\
\hline Ammonium nitrate & 0.22 & 0.11 & 0.11 & 0.67 & 0.48 & 0.19 & 2.88 & 2.44 & 0.44 \\
\hline POA & 0.08 & 0.05 & 0.03 & 1.23 & 0.88 & 0.35 & 2.88 & 2.11 & 0.77 \\
\hline SOA & 0.17 & 0.08 & 0.09 & 0.28 & 0.18 & 0.10 & 0.38 & 0.26 & 0.12 \\
\hline BC & 0.01 & 0.006 & 0.004 & 0.23 & 0.18 & 0.05 & 0.52 & 0.42 & 0.10 \\
\hline (Total) & 0.89 & 0.44 & 0.45 & 5.28 & 3.99 & 1.29 & 9.40 & 7.24 & 2.16 \\
\hline Sea salt ${ }^{\mathrm{a}}$ & - & - & - & 4.96 & 1.64 & 3.32 & - & - & - \\
\hline
\end{tabular}

${ }^{\mathrm{a}}$ Present-day (20C) sea salt concentrations are used in the calculation of preindustrial (PI) and $21 \mathrm{C} N_{c}$ fields. Units are Tg dry mass. POA, primary organic aerosol; SOA, secondary organic aerosol; BC, black carbon. NH, Northern Hemisphere; SH, Southern Hemisphere. 
(a)

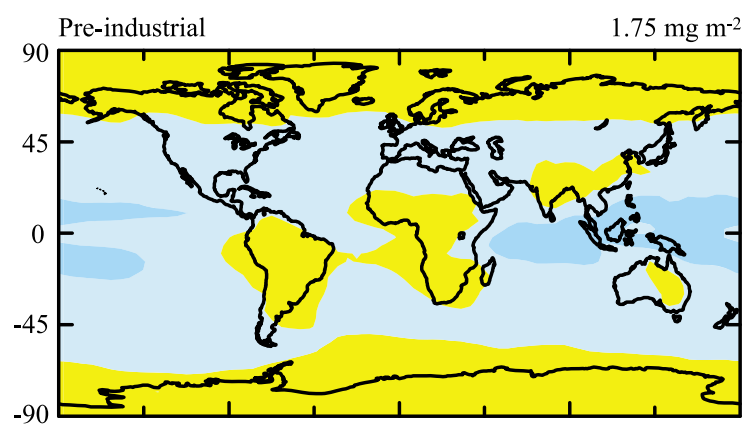

(b)
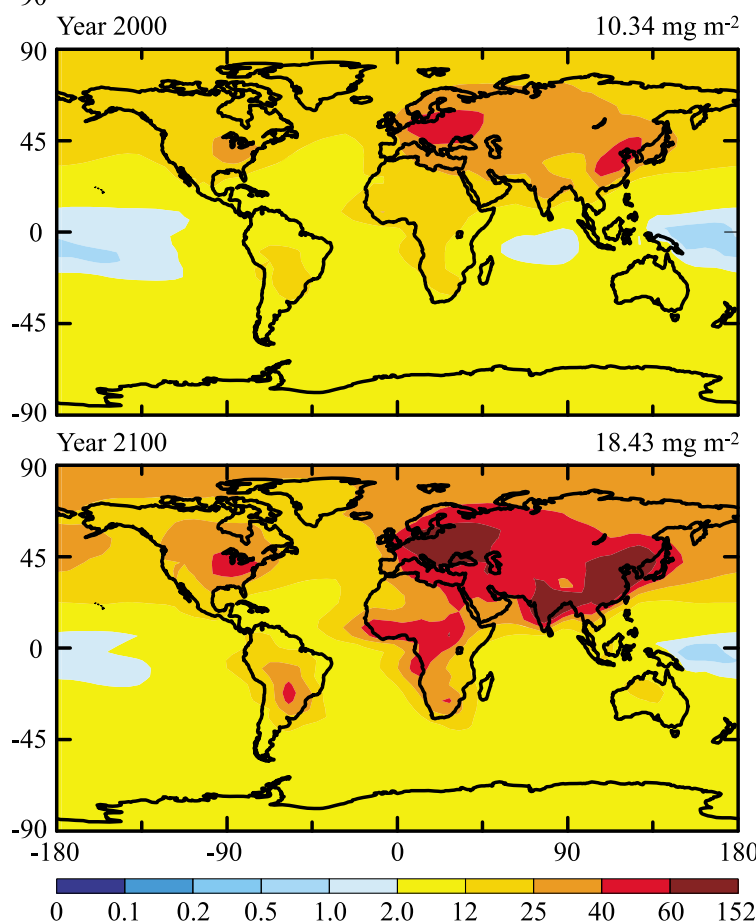

Figure 2. Annual mean total column burden $\left(\mathrm{mg} \mathrm{m}^{-2}\right)$ of sulfate, nitrate, ammonium, primary organic aerosol (POA), secondary organic aerosol (SOA), and black carbon (BC) for (a) preindustrial (PI), (b) 20th century (20C), and (c) 21 st century $(21 \mathrm{C})$. Global average values are given in the upper right corner of each plot.

[11] Three simulations with the CACTUS Unified Model were carried out, each using emissions of aerosols, aerosol precursors, and ozone precursors corresponding to PI, 20C, and $21 \mathrm{C}$, while GHG were held at present-day levels in all the simulations. Emissions for $20 \mathrm{C}$ and $21 \mathrm{C}$ are based on Intergovermental Panel on Climate Change (IPCC) Special Report on Emissions Scenarios (SRES) A2. Emissions for PI are based on those for $20 \mathrm{C}$, with relevant scaling (as detailed by Liao and Seinfeld [2005] and Liao et al. [2006]). All three simulations were initiated by an equilibrium climate corresponding to $20 \mathrm{C} \mathrm{GHG}$ and integrated for 6 years. Since the levels of GHG are fixed throughout the simulations, the differences between the derived PI, 20C and 21C aerosol concentrations result entirely from emission changes. Results from the last 5 years in each simulation are averaged to obtain a grid-by-grid, annual cycle of monthly averaged aerosol mass concentrations. These aerosol concentrations are used later in deriving the offline $N_{c}$ values (section 2.2) and also to account for aerosol direct radiative effects (ADE) in the climate simulations (section 2.3.3).

[12] Table 2 lists the predicted global and hemispheric annual burdens of ammonium bisulfate, ammonium nitrate, POA, SOA, BC, and sea salt aerosols, derived for PI, 20C, and 21C. Each of the above species shows significant increase from PI to $20 \mathrm{C}$. From $20 \mathrm{C}$ to $21 \mathrm{C}$, sulfates are predicted to decrease owing to reductions in projected $\mathrm{SO}_{2}$ emissions; nitrate levels are predicted to increase more than fourfold, while POA and $\mathrm{BC}$ are predicted to double. Figure 2 shows the annual global mean column burdens of anthropogenic aerosol for PI, 20C, and 21C. Increases in peak concentrations are predicted over heavily industrialized and populated areas of South and East Asia, Europe, and the eastern United States. Outflows from the major biomass burning regions in South America and western Africa are also prominent. Predicted global column burdens of sea salt for $20 \mathrm{C}$ are shown in Figure 3. With a predicted global burden of $4.96 \mathrm{Tg}$, sea salt concentrations are highest over the southern ocean and the midlatitude ocean over Northern Hemisphere (NH), corresponding to the strong winds that lead to high emissions in these areas.

\subsection{GISS-TOMAS Model, FN Activation Parameterization, and Derivation of Aerosol- $N_{c}$ Relationships}

[13] GISS-TOMAS and the NS activation parameterization (with the mass transfer corrections as implemented in FN) are used to provide the diagnostic relationship between aerosol levels and $N_{c}$. The size-resolved TOMAS microphysics module simulates aerosol number concentration, size distribution, composition, and $\mathrm{CCN}$ online within the GISS GCM II'; detailed descriptions are provided by Adams and Seinfeld [2002] for sulfate simulations and Pierce and Adams [2006] for the implementation of sea salt aerosol. In brief, the module tracks both the number and the mass of aerosols in each size bin in the aerosol distribution. A sectional approach is applied to define the boundaries of 30 size bins (spanning approximately dry diameters of 0.01 to $10 \mu \mathrm{m}$ ), in terms of dry aerosol mass. Microphysical processes include coagulation, condensation/evaporation, nucleation,

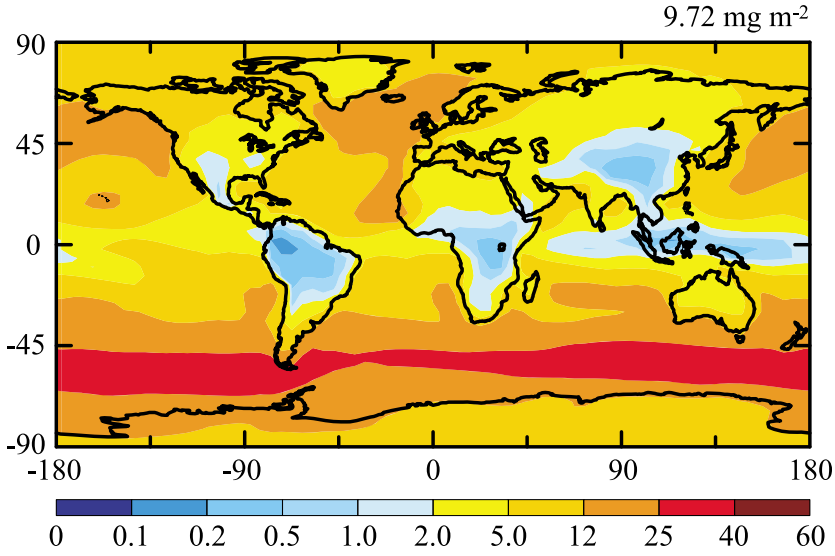

Figure 3. Annual mean column burden of sea salt $\left(\mathrm{mg} \mathrm{m}^{-2}\right)$ for $20 \mathrm{C}$. Global average values are given in the upper right corner. 
and in-cloud sulfur oxidation. Sulfate is assumed to exist as ammonium bisulfate and to be internally mixed with sea salt. The NS activation parameterization is then applied online to compute nucleation scavenging of aerosol and $N_{c}$ from the aerosol simulation. NS is a comprehensive and efficient formulation, which has been evaluated extensively with numerical simulations [Nenes and Seinfeld, 2003; Fountoukis and Nenes, 2005], as well as in situ measurements [Meskhidze et al., 2005; Fountoukis et al., 2007]. NS and FN is based on the framework of an ascending adiabatic cloud parcel; $N_{c}$ is determined by the maximum supersaturation, $s_{\max }$, which is controlled by the water vapor balance and is obtained by classifying the droplets by proximity to their critical diameter ("population splitting"). In this study, a single cloud base updraft velocity of $0.6 \mathrm{~m} \mathrm{~s}^{-1}$ over land and $0.3 \mathrm{~m} \mathrm{~s}^{-1}$ over ocean is prescribed, based on in situ measurements of updraft velocity in stratocumulus clouds [Fountoukis et al., 2007]. Using a single updraft velocity gives optimal closure between observations and theory for cloud droplet calculations in cumulus and stratocumulus clouds, provided that it expresses the average vertical velocity distribution in the boundary layer [e.g., Meskhidze et al., 2005; Peng et al., 2005; Fountoukis et al., 2007]. On the basis of the calculations by R. Morales and A. Nenes (Characteristic updrafts for computing distribution-averaged cloud droplet number, autoconversion rate and effective radius, submitted to Geophysical Research Letters, 2009) and the conclusions from previous works [e.g., Meskhidze et al., 2005; Fountoukis et al., 2007], $N_{c}$ computed as an integral over a updraft velocity distribution is close to that computed at a single, distribution-averaged updraft velocity, and the difference is at most $10 \%$. For grid cells that contain both ocean and land, a weighted average of droplet number is computed based on the fractional coverage. The effective water vapor uptake coefficient (which affects the water vapor mass transfer coefficient during droplet formation) is set to 0.06 , following Fountoukis et al. [2007]. The model was integrated for 2 years with present-day emissions of sulfur and sea salt; monthly, grid-by-grid CCN spectra are then derived from the simulations of the second year.

[14] On the basis of the monthly averaged CCN spectra obtained from GISS-TOMAS, an aerosol- $N_{c}$ relationship is derived for each grid cell and month as follows: the aerosol concentration is varied between 0.05 and 5 times the average concentration, and the corresponding $N_{c}$ is computed by application of FN (using the same updraft velocity and water vapor uptake coefficient as in the online simulation). The relationship between aerosol amount (expressed in terms of molar concentration of total soluble ions from sulfate and sea salt, $m_{i}$, in mole $\mathrm{m}^{-3}$ air) and $N_{c}\left(\mathrm{~m}^{-3}\right)$ is then correlated in the format proposed by Boucher and Lohmann [1995],

$$
\log _{10} N_{c}=A+B \log _{10} m_{i}
$$

[15] The coefficients $A$ and $B$ are computed for each grid cell in each month by least mean squares optimization. Thereby, geographic and seasonal variations of aerosolcloud interactions are represented by the values of the two coefficients. The correlation coefficients in all fits range between 0.85 and 0.99 . The diagnostic formulation developed here is particularly useful for GCM studies because it is based on (1) aerosol soluble ions rather than mass or composition of certain aerosol species, and therefore can be applied broadly to global models; and on (2) detailed cloud microphysics and activation models, yet is computationally efficient as compared to an online detailed cloud microphysical module. In general, over pristine areas, coefficient $\mathrm{A}$ in equation $(1)=1.7$ to 2.4 , and coefficient $\mathrm{B}=0.6$ to 1.0 ; over highly polluted areas, $\mathrm{A}=2.4$ to 3.0 , and $\mathrm{B}=0.4$ to 0.6. As a comparison, Boucher and Lohmann [1995], based on mass of sulfate aerosols, derived $\mathrm{A}=2.06$ and $\mathrm{B}=0.48$ over ocean and $\mathrm{A}=2.240$ and $\mathrm{B}=0.257$ over land (stratiform clouds); Quaas et al. [2006] correlated $N_{c}$ with finemode aerosol optical depth from satellite data and yielded globally $\mathrm{A}=2.17$ and $\mathrm{B}=0.30$.

[16] To obtain the offline, monthly averaged $N_{c}$ values for the equilibrium climate simulations, the 9 layer aerosol mass concentrations of sulfate, nitrate, ammonium, carbonaceous, and sea salt aerosols derived in the Unified Model (section 2.1) are converted to soluble ion concentrations. We assume sea salt distributions in PI and $21 \mathrm{C}$ are the same as in $20 \mathrm{C}$, since the uncertainties related to sea salt concentrations may be significant for PI and 21C [Liao and Seinfeld, 2005], and the focus of the present study is on the impacts of anthropogenic aerosols. We assume that ammonium bisulfate, ammonium nitrate, and sea salt aerosols are fully soluble, POA and SOA is $80 \%$ soluble [Limbeck and Puxbaum, 2000; Bougiatioti et al., 2009], BC is insoluble, and each of the soluble species forms an ideal solution. Since most carbonaceous compounds do not dissociate significantly, a van't Hoff factor of 1.0 is assumed for soluble organic aerosols [e.g., Giebl et al., 2002; Raymond and Pandis, 2002; Sun and Ariya, 2006; Dinar et al., 2006]. A molar mass of $0.2 \mathrm{~kg} \mathrm{~mole}^{-1}$ is used to convert mass concentration into molar concentration for organic aerosols [Asa-Awuku et al., 2008; Engelhart et al., 2008; Asa-Awuku et al., 2009; Bougiatioti et al., 2009], a rough surrogate for the diversity of organics traced in the Unified Model, of which the molar masses span between 0.09 and $0.3 \mathrm{~kg} \mathrm{~mole}^{-1}$. The $N_{c}-m_{i}$ formulations with the derived monthly coefficients at each grid cell were then applied to calculate $N_{c}$ for PI, 20C, and $21 \mathrm{C}$ conditions. A lower limit of $20 \mathrm{~cm}^{-3}$ is prescribed for $N_{c}$ based on annual average $N_{c}$ in pristine marine environments [e.g., Seinfeld and Pandis, 1998; Glantz and Noone, 2000; Bennartz, 2007]. The monthly $N_{c}$ values were interpolated from a vertical resolution of 9 layers into 23 layers, according to the $\sigma$ levels of the GISS-II' and GISS III GCMs, ensuring conservation of total $N_{c}$ in the entire column.

[17] Figure 4 shows the derived annual mean $N_{c}$ at the lowest model level $(972 \mathrm{hPa}$ ) for PI, 20C, and 21C, with the results before and after applying the minimum $N_{c}$ value. Assuming a minimum $N_{c}$ of $20 \mathrm{~cm}^{-3}$ (right column) would increase $N_{c}$ over pristine ocean in PI and $20 \mathrm{C}$ conditions, whereas the change in $21 \mathrm{C}$ is essentially negligible. Figures $5 \mathrm{a}$ and $5 \mathrm{~b}$ show the changes from PI to $20 \mathrm{C}$ and from $20 \mathrm{C}$ to $21 \mathrm{C}$. The predicted increase in annual mean $N_{c}$ value in $850 \mathrm{hPa}$ level is $58.3 \mathrm{~cm}^{-3}$ from PI to $20 \mathrm{C}$ and $31.9 \mathrm{~cm}^{-2}$ from $20 \mathrm{C}$ to $21 \mathrm{C}$. The areas predicted to exhibit a significant $N_{c}$ increase from PI to $20 \mathrm{C}$ are closely related to areas of enhanced concentrations of anthropogenic sulfate, nitrate, ammonium, and organic aerosols (Figure 2). For changes between $20 \mathrm{C}$ and $21 \mathrm{C}$ (Figure 5b), large increases 


$$
\left[\min . N_{c}=0 \mathrm{~cm}^{-3}\right]
$$

(a)

(b)

(c)
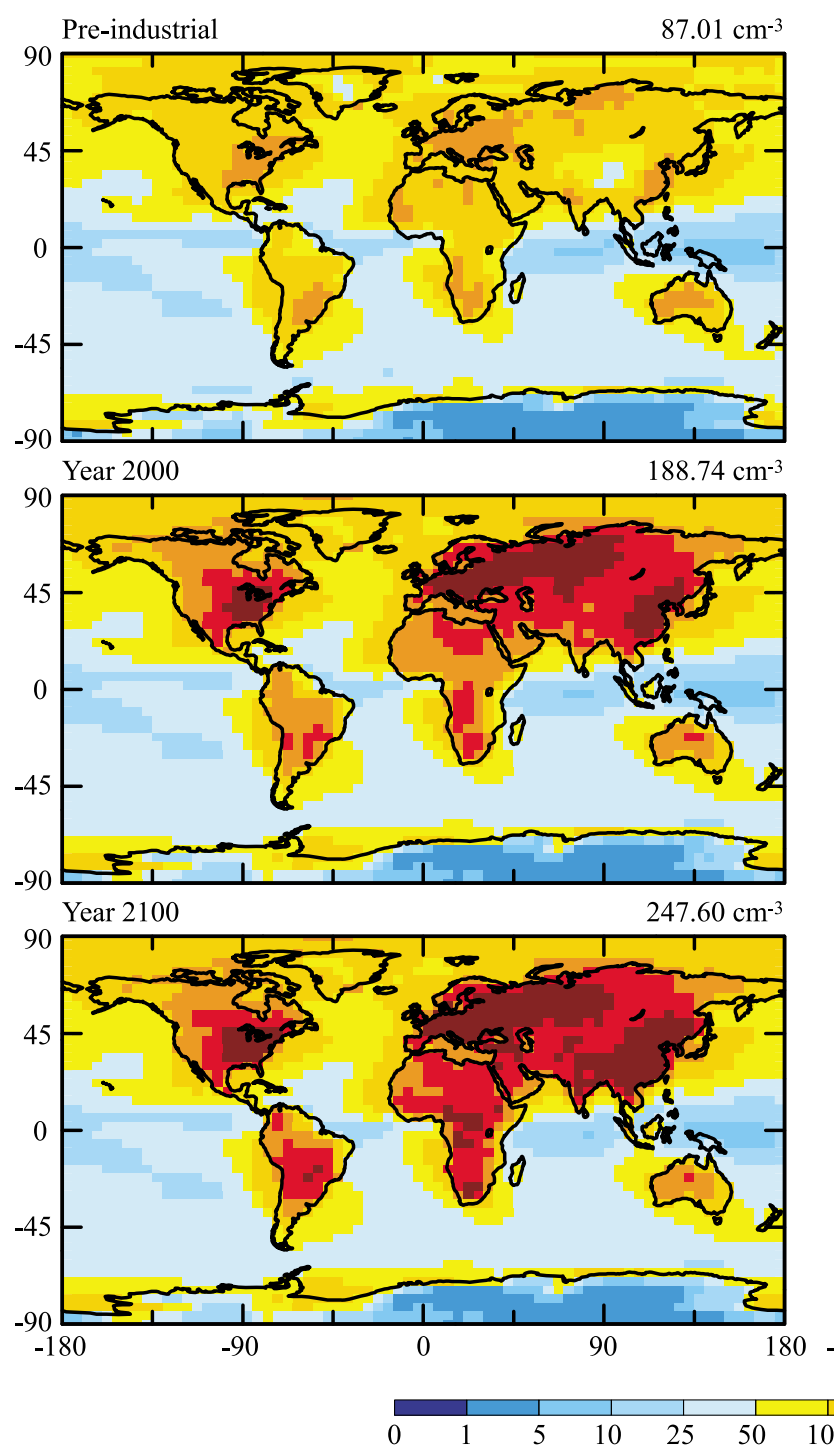

\begin{tabular}{llllllllllll}
\hline & & & & $\mid$ & $\mid$ & $\mid$ & $\mid$ & $\mid$ & $\mid$ & & \\
0 & 1 & 5 & 10 & 25 & 50 & 100 & 250 & 500 & 1000 & 2500
\end{tabular}

Figure 4. Predicted annual mean $N_{c}$ at the lowest model layer (972 hPa) for (a) PI, (b) 20C, and (c) $21 \mathrm{C}$. (left) Results assuming no minimum $N_{c}$ value. (right) Results assuming a minimum value of $N_{c}=20 \mathrm{~cm}^{-3}$. Global average values are given in the upper right corner of each plot.

in near-surface $N_{c}$ are predicted over the aerosol source regions over China, South America, and southern Africa where all anthropogenic aerosols are predicted to increase in 21C. Over the source regions of western Europe and eastern United States, the predicted future decrease in sulfate aerosols owing to sulfate precursor emission regulation is canceled by the increase of nitrate and OA, leading to higher $N_{c}$ in $21 \mathrm{C}$. Over northern high latitudes where the predicted decrease of sulfate aerosols dominates the future change of soluble aerosol burdens, $N_{c}$ is estimated to decrease. The enhancement in $N_{c}$ from $20 \mathrm{C}$ to $21 \mathrm{C}$ is $58 \%$ of that from PI to $20 \mathrm{C}$, although the predicted increase in aerosol mass column (Table 2) is of comparable magnitude in each period (+4.39 Tg between PI and 20C; $+4.13 \mathrm{Tg}$ between $20 \mathrm{C}$ and $21 \mathrm{C})$. The value of $N_{c}$ is correlated with aerosol soluble mass by the power law in equation (1), and the coefficient $B$ in equation (1) is mostly between 0.5 and 1.0. Therefore the increase in predicted $N_{c}$ has a smaller magnitude as compared with the increase in aerosol column mass.

[18] Note that the $N_{c}-m_{i}$ correlations are developed based on CCN predictions of sulfate and sea salt only, while the $N_{c}$ values are calculated based on mass of sulfate, nitrate, ammonium, soluble OA, and sea salt. The version of the TOMAS model used in the present study does not include nitrate and carbonaceous aerosols, therefore the chemical and number concentration effects of nitrate and carbonaceous aerosols on the CCN spectrum are not included in the derivation of the $N_{c}-m_{i}$ correlations.

\subsection{GISS III GCM}

[19] Detailed descriptions and evaluation of the GISS III are provided by Rind et al. [2007]. In addition to the 
(a)

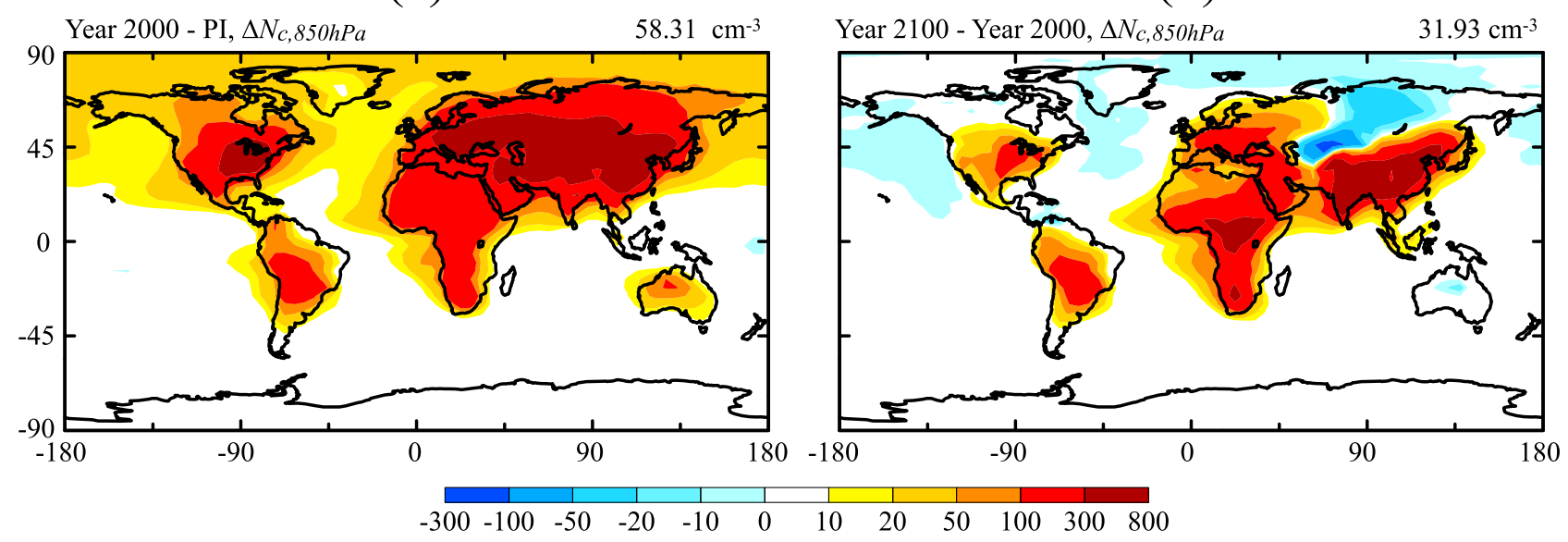

(c)

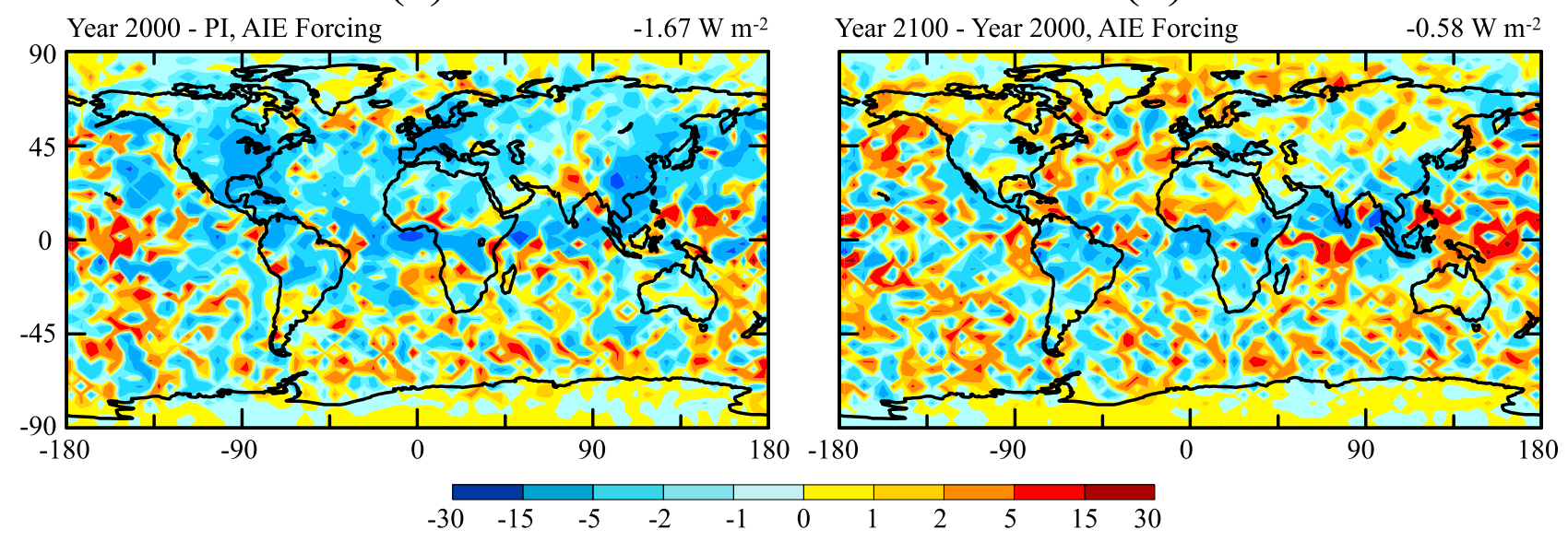

Figure 5. (top) Changes in annual mean $N_{c}$ at the $850 \mathrm{hPa}$ level from (a) $\mathrm{PI}$ to $20 \mathrm{C}$ and (b) $20 \mathrm{C}$ to $21 \mathrm{C}$. (bottom) Annual mean full aerosol indirect effects (AIE) forcing from (c) PI to 20C and (d) 20C to 21C. Global average values are given in the upper right corner of each plot. Displayed are results of setting minimum $N_{c}$ values $=20 \mathrm{~cm}^{-3}$.

increase in vertical resolution from $9 \sigma$-layers in GISS GCM II' (between surface and $10 \mathrm{hPa}$ ) to $23 \sigma$-layers (between surface and $0.002 \mathrm{hPa}$ ), major modifications in GISS III include more sophisticated treatments in downdraft entrainment and the detrainment of cumulus condensate into an anvil similar to stratiform cloud, the addition of compensatory subsidence in moisture advection, new formulations of boundary layer temperature, moisture and scalar fluxes, and turbulent kinetic energy, as well as more correlated $\mathrm{k}$ intervals in the radiative scheme. Compared to the other commonly used version of GISS GCM, the GISS ModelE, GISS III predicts different liquid water path, interhemispheric transport, precipitation over land in the monsoon region, total cloud cover and albedo, and gravity wave drag [Rind et al., 2007], owing to differences in detailed treatments. The stratiform cloud scheme in GISS III is based mainly on the work of Del Genio et al. [1996]. In order to simulate AIE-related response in cloud optical properties, precipitation, and radiation, the formulations of cloud optical depth and autoconversion rate in the stratiform cloud scheme were revised, as described below.

\subsubsection{Modification of Stratiform Cloud Scheme:} Droplet Effective Radius and Cloud Optical Depth

[20] The stratiform cloud scheme diagnoses the cloud radiative properties based on the cloud optical depth $\tau$ and the effective droplet radius $r_{e}$, which is related to the volume-weighted mean droplet radius $r_{v}$ by

$$
r_{e}=\kappa^{-\frac{1}{3}} r_{v}
$$

[21] A single value of 0.48 is chosen for the constant $\kappa$ in the standard GISS III [Menon et al., 2002; Rind et al., 2007], which corresponds to an effective variance of 0.2 . In the standard algorithm in GISS III, $r_{v}$ is determined by an empirical scaling based on the value of $\mu$, which implicitly assumes a constant value of $N_{c}=60 \mathrm{~cm}^{-3}$ over ocean and $N_{c}=170 \mathrm{~cm}^{-3}$ over land [Del Genio et al., 1996]. In the present study, to include the cloud albedo effect in stratiform clouds, the following equation is applied,

$$
r_{v}=\left[\frac{3 \mu}{4 \pi N_{c} \rho_{w}}\right]^{\frac{1}{3}}
$$


so that $r_{v}$ is determined by $\mu$ and the offline $N_{c}\left(\mathrm{~m}^{-3}\right)$ values imported to each grid cell on a monthly basis. Therefore, $r_{e}$ and $\tau$ are controlled by the spatial and seasonal variations of $N_{c}$, which are driven by the changes in aerosol mass and aerosol-cloud interactions. Note that equation (3) is also applied to compute the radius in droplet evaporation. Additional modifications to the scheme of Del Genio et al. [1996] include a change in the value of $\kappa(0.67$ over land and 0.80 over ocean [Martin et al., 1994]) to reflect the broader distributions of terrestrial clouds (with respect to oceanic), constraints on the minimum and maximum values of $r_{e}(2$ and $20 \mu \mathrm{m}$, respectively), and a constraint of in-cloud liquid water content $<3 \mathrm{~g} \mathrm{~m}^{-3}$. The above modifications are applied to pure liquid stratiform clouds only (temperature $>4^{\circ} \mathrm{C}$ over ocean, and $>-10^{\circ} \mathrm{C}$ over land); ice stratiform clouds (temperature $<-40^{\circ} \mathrm{C}$ ), mixed-phase stratiform clouds, as well as convective clouds, follow the scheme of Del Genio et al. [1996].

\subsubsection{Modification of Stratiform Cloud Scheme: Autoconversion Rate}

[22] The basic autoconversion formulation in GISS III is related to that given by Sundqvist et al. [1989],

$$
\left.\frac{d q_{l}}{d t}\right|_{a u t}=C_{0} q_{l}\left\{1-e^{\left[-\left(\frac{\mu}{\mu_{\text {crit }}}\right)^{4}\right]}\right\}
$$

where $q_{l}$ is the cloud liquid water mixing ratio, $C_{0}$ is the limiting autoconversion rate $\left(\mathrm{s}^{-1}\right)$, and $\mu_{\text {crit }}$ is the critical incloud water content for the onset of rapid conversion. To explicitly relate $q_{l}$ to $N_{c}$, this parameterization is replaced with that developed by Khairoutdinov and Kogan [2000] (KK hereafter), and modified to account for the fractional cloudiness in each GCM grid cell,

$$
\left.\frac{d q_{l}}{d t}\right|_{\text {aut }}=-1350 \gamma b\left(\frac{q_{l}}{b}\right)^{2.47} N_{c}^{-1.79}
$$

To ensure that the same radiative balance is maintained before and after the replacement of the autoconversion parameterization, a tuning parameter $\gamma$ is used [Hoose et al., 2008]. In the typical ranges of liquid water and $N_{c}$, autoconversion rates calculated by the KK scheme can be 1 to 1000 times smaller than those by the Sundquist scheme [Penner et al., 2006; Hsieh et al., 2009]. When implementing the KK scheme in GISS III, proper adjustment to the autoconversion rates is needed to avoid the unintentional increase in liquid water path (LWP) and the subsequent "drift" toward a cooler climate. The value of $\gamma$ is determined by minimizing the imbalance of top-of-atmosphere (TOA) radiation, the same approach adopted by Hoose et al. [2008]. Starting from a present-day equilibrium climate predicted by the standard GISS III with fixed present-day SST and sea ice (the HadISST1 observed climatology for 1993 to 2002 [Rayner et al., 2003]), the modified GCM is integrated for 1 year, with a specific value of $\gamma$. The annual mean TOA net radiation is diagnosed. By testing various values between 1 and $100, \gamma=8.0$ produces the closest net TOA radiation balance and thus is chosen.

[23] A new Q-flux field is derived to secure consistency between the ocean model and the atmospheric model that has $20 \mathrm{C}$ GHG levels and $20 \mathrm{C} N_{c}$ with modified stratiform cloud scheme. This Q-flux ocean is then used in all AIE equilibrium climate simulations described in section 4 .

\subsubsection{Aerosol Direct Effect in GISS III}

[24] The sulfate, nitrate, ammonium and carbonaceous aerosol masses derived by the Unified Model are also to be used in the equilibrium climate simulations to account for the anthropogenic aerosol direct effect in GISS III. Calculation of the anthropogenic aerosol direct effect follows Chen et al. [2007]. The monthly averaged aerosol mass concentrations derived by the CACTUS Unified Model (section 2.1) are interpolated into 23 layers accordingly. Internal mixing of ammonium sulfate, ammonium nitrate, BC, POA, SOA and aerosol associated water is assumed. A standard gamma size distribution is assumed for the aerosol mixture with a surface area-weighted dry radius $=0.3 \mu \mathrm{m}$ and variance $=0.2$. The density of the internally mixed aerosol is computed as the mass-averaged density of water and dry aerosols. Refractive indices are derived based on a volume-weighted mixing rule. The refractive index of dry nitrate is assumed the same as that of dry sulfate [Toon et al., 1976], while the refractive indices for organic carbon, $\mathrm{BC}$, and water are from d'Almeida et al. [1991] (organic carbon as "water soluble," BC as "soot"). Mie theory is applied to determine extinction efficiency, single-scattering albedo, and asymmetry parameter from a lookup table, which are then supplied to the radiation scheme of the GCM to calculate the aerosol optical depth and the radiation fluxes. The internal mixing assumption yields a relatively high absorption efficiency per unit mass of BC [e.g., Haywood et al., 1997; Myhre et al., 1998; Jacobson, 2000; Chung and Seinfeld, 2002, 2005].

[25] The ADE of sea salt and dust is accounted for by using the background, present-day sea salt and dust optical depth climatology provided in the standard GISS III. This sea salt/dust climatology is identical to that in GISS ModelE, [e.g., Schmidt et al., 2006]. All the simulations used the same sea salt and dust ADE, so the climatic effects of these natural aerosols are removed when the simulations are differentiated in pairs. The ADE forcing in the present study results solely from the changes in the internal mixture of anthropogenic aerosols (i.e., sulfate, nitrate, ammonium, and carbonaceous particles) predicted by the Unified Model.

\section{Radiative Forcing}

\subsection{Radiative Forcing of GHG, ADE, and AIE}

[26] Table 3 summarizes the radiative forcings of GHG, $\mathrm{ADE}$, and AIE in the present study. For GHG and ADE, the forcings are determined by the instantaneous change in net radiative fluxes at the tropopause (without adjustment in stratospheric temperature). The calculations are carried out with prescribed present-day SST and sea ice, using parallel calls of the radiation scheme. Between the present day and year 2100, the changes in GHG and ADE in the simulations are estimated to result in forcings of $+6.47 \mathrm{~W} \mathrm{~m}^{-2}$ and $+0.12 \mathrm{~W} \mathrm{~m}^{-2}$, respectively. These values are close to those reported by Chen et al. [2007] $\left(+6.58 \mathrm{~W} \mathrm{~m}^{-2}\right.$ for GHG and $+0.18 \mathrm{~W} \mathrm{~m}^{-2}$ for ADE), which were derived using the 9 layer GISS GCM II' with identical offline aerosol fields and similar GHG levels to the present work. 
Table 3. AIE, ADE, and GHG Forcing in the Present Study

\begin{tabular}{lcc}
\hline & $20 \mathrm{C}$ to $\mathrm{PI}\left(\mathrm{W} \mathrm{m}^{-2}\right)$ & $21 \mathrm{C}$ to $20 \mathrm{C}\left(\mathrm{W} \mathrm{m}^{-2}\right)$ \\
\hline Instantaneous ADE forcing & - & +0.12 \\
Instantaneous GHG forcing & - & +6.47 \\
AIE forcing, full & $-1.67(-1.70,2 \%)$ & $-0.58(-0.65,12 \%)$ \\
\hline
\end{tabular}

${ }^{\mathrm{a}} \mathrm{AIE}$ forcing is derived with prescribed sea surface temperature (SST) and the modified stratiform cloud scheme, allowing full response of cloud water and precipitation. AIE forcing is defined as the change in net (shortwave + longwave) cloud forcing (i.e., all-sky minus clear-sky net radiative fluxes) at top of atmosphere (TOA). Values in parenthesis are the AIE forcing with minimum $N_{c}=10 \mathrm{~cm}^{-3}$ and the percentage change relative to the case of minimum $N_{c}=20 \mathrm{~cm}^{-3}$. ADE, aerosol direct effect. GHG, greenhouse gas.

[27] Because AIE involves feedback mechanisms, the concept of instantaneous radiative forcing cannot be applied, especially when the cloud lifetime effect is considered. Total AIE radiative forcing has to be determined by diagnosing the changes in cloud forcing $(\mathrm{CF}$, i.e., all-sky minus clearsky radiative fluxes), allowing at least the cloud water and precipitation to respond, as described in the IPCC report [Forster et al., 2007].

[28] Total AIE radiative forcing is derived by following the literatures summarized in IPCC AR4 [Denman et al., 2007]. The full AIE forcing calculations in the present studies includes three simulations using prescribed presentday SST and sea ice and the modified stratiform cloud scheme, each with the offline $N_{c}$ values for PI, 20C, and $21 \mathrm{C}$, respectively. The GHG is fixed to levels in 2000 in all three calculations. Cloud and precipitation are allowed to respond to different $N_{c}$ values, while most of the temperature response is suppressed with the fixed SST. Therefore, both cloud albedo and lifetime effects are taken into account. The simulations were integrated for 20 years; with a 5 year spin-up time, the net cloud forcing (CF, i.e., all-sky minus clear-sky net radiative fluxes) at TOA over the last 15 years were averaged and compared (Table 3 and Figure 5). The predicted global mean full AIE forcing is $-1.67 \mathrm{~W} \mathrm{~m}^{-2}$ for perturbation of $N_{c}$ from PI to 20C, lying within the range to total AIE forcing reported in the literature $(-0.29$ to $-2.41 \mathrm{~W} \mathrm{~m}^{-2}$ ) [e.g., Lohmann and Feichter, 2005; Denman et al., 2007; Forster et al., 2007; Kirkevåg et al., 2008b]. The full AIE forcing is $-0.58 \mathrm{~W} \mathrm{~m}^{-2}$ for perturbation of $N_{c}$ from $20 \mathrm{C}$ to $21 \mathrm{C}$. This value is larger than that predicted by Kristjansson [2002] $\left(-0.02 \mathrm{~W} \mathrm{~m}^{-2}\right)$, which is based on the IPCC A2 emission scenario from $20 \mathrm{C}$ to $21 \mathrm{C}$ but considered only changes in anthropogenic sulfate and $\mathrm{BC}$ aerosols, implying that the future AIE forcing is mainly contributed by the increase in nitrate and organic aerosols.

\subsection{Sensitivity of AIE Forcing to the Lower Limit of $\boldsymbol{N}_{c}$ Concentrations}

[29] The AIE forcing can be sensitive to the minimum $N_{c}$ concentrations assumed in the calculations [Lohmann and Feichter, 2005]. To explore this sensitivity of the AIE forcing in the present study, we repeat the above AIE forcing calculations with a minimum $N_{c}=10 \mathrm{~cm}^{-3}$ (Table 3; numbers in parenthesis). When the minimum $N_{c}$, is reduced, the magnitude of the AIE forcing between PI and $20 \mathrm{C}$ is predicted to be slightly enhanced $(2 \%)$. Because predicted
$N_{c}$ fields in pristine regions are below the minimum value (Figure 4) in both PI and 20C conditions, the magnitudes of $\mathrm{CF}$ in PI and 20C decrease almost equally when a smaller minimum $N_{c}$ value is used. Thus, the AIE forcing, which is the difference of CF between PI and 20C, only shows a limited change with the value of minimum $N_{c}$. However, the enhancement of AIE forcing between $20 \mathrm{C}$ and $21 \mathrm{C}$ is more significant $(+12 \%)$. The $N_{c}$ fields in $21 \mathrm{C}$ are generally above the minimum value. Since the $\mathrm{CF}$ in $21 \mathrm{C}$ exhibits small change and the $\mathrm{CF}$ in $20 \mathrm{C}$ decreases with smaller minimum $N_{c}$, the AIE forcing between $20 \mathrm{C}$ and $21 \mathrm{C}$ is predicted to increase when the minimum $N_{c}$ is set to $10 \mathrm{~cm}^{-3}$.

[30] As compared to the previous studies, the present works predicts a weaker sensitivity of present-day AIE forcing to the lower limit of $N_{c}$. For example, Lohmann and Feichter [2005] showed that an increase of minimum $N_{c}$ from 10 to $40 \mathrm{~cm}^{-3}$ results in a higher predicted present-day AIE forcing from -1.9 to $-1.1 \mathrm{~W} \mathrm{~m}^{-2}$ (72\%); Kirkevåg et al. [2008b] found that a global increase in $N_{c}$ by $15 \mathrm{~cm}^{-3}$ changes the present-day AIE forcing from -2.34 to $-1.36 \mathrm{~W}$ $\mathrm{m}^{-2}$ (42\%); Hoose et al. [2009] calculated a reduction of global mean shortwave (SW) CF from -1.88 to $-0.62 \mathrm{~W} \mathrm{~m}^{-2}$ $(67 \%)$ when minimum $N_{c}$ is increased from 0 to $40 \mathrm{~cm}^{-3}$. This sensitivity is associated with the differences in original $N_{c}$ values (i.e., before any minimum $N_{c}$ value is applied) predicted over pristine ocean between PI and present-day conditions.

\section{Experimental Setup for Equilibrium Climate Simulations With GISS III GCM}

[31] The experimental setups of the equilibrium climate simulations with GISS III are summarized in Table 4. The nomenclature of the simulations is as follows: (1) Upper case letters denote the forcing mechanisms imposed on each simulation, with $G$ for greenhouse gas forcing, $D$ for aerosol Direct effect, and $I$ for aerosol Indirect effect; and (2) subscripts denote the levels of the forcing agents, with PI for

Table 4. Experimental Design of the Equilibrium Simulations with GISS III GCM ${ }^{\mathrm{a}}$

\begin{tabular}{lcccc}
\hline Simulation $^{\mathrm{b}}$ & $\mathrm{GHG}^{\mathrm{c}}$ & $\mathrm{ADE}^{\mathrm{d}}$ & $\mathrm{AIE}^{\mathrm{e}}$ & Years of Integration \\
\hline$G D_{20 \mathrm{C}}$ & $20 \mathrm{C}$ & $20 \mathrm{C}$ & - & 100 \\
$G D_{21 \mathrm{C}}$ & $21 \mathrm{C}$ & $21 \mathrm{C}$ & - & 100 \\
$G D_{20 \mathrm{C}} I_{20 \mathrm{C}}$ & $20 \mathrm{C}$ & $20 \mathrm{C}$ & $20 \mathrm{C}$ & 30 \\
$G D_{20 \mathrm{C}} I_{\mathrm{PI}}$ & $20 \mathrm{C}$ & $20 \mathrm{C}$ & $\mathrm{PI}$ & 30 \\
$G D_{20 \mathrm{C}} I_{21 \mathrm{C}}$ & $20 \mathrm{C}$ & $20 \mathrm{C}$ & $21 \mathrm{C}$ & 30 \\
$G D_{21 \mathrm{C}} I_{21 \mathrm{C}}$ & $21 \mathrm{C}$ & $21 \mathrm{C}$ & $21 \mathrm{C}$ & 30 \\
\hline
\end{tabular}

${ }^{\mathrm{a}} \mathrm{GCM}$, general circulation model.

${ }^{\mathrm{b}}$ In the abbreviations, upper case letters denote the forcings imposed in each simulations: $G$, greenhouse gases; $D$, aerosol direct effects; $I$, aerosol indirect effects. The subscripts denote the levels of the forcing: PI, preindustrial; 20C, year 2000; $21 \mathrm{C}$, year 2100 . The first two simulations were carried out with the standard GISS III, while the last four simulations were performed with the modified GISS III.

${ }^{\mathrm{c}}$ For $20 \mathrm{C}$ levels, $\mathrm{CO}_{2}=367 \mathrm{ppmv}, \mathrm{CH}_{4}=1668$ ppbv, $\mathrm{N}_{2} \mathrm{O}=315 \mathrm{ppbv}$, $\mathrm{CFC}=11=260$ pptv, and $\mathrm{CFC}=12=520$ pptv. For $21 \mathrm{C}$ levels, $\mathrm{CO}_{2}=856$ ppmv, $\mathrm{CH}_{4}=3578$ ppbv, $\mathrm{N}_{2} \mathrm{O}=445$ ppbv, CFC-11 = 44 pptv, and CFC$12=216$ pptv.

${ }^{\mathrm{d}}$ From offline, monthly imposed aerosols of internally mixed sulfate, nitrate, ammonium, BC, POA, SOA, and water.

e From offline, monthly imposed $N_{c}$ in the calculation of optical depth and autoconversion in warm stratiform clouds. 
Table 5. Global Annual Mean Values of Key Climate Variables in the Present-Day Equilibrium Simulations With and Without Explicit Droplet Dependence in Stratiform Clouds

\begin{tabular}{lcc}
\hline Climate Variable $^{\mathrm{a}}$ & $G D_{20 \mathrm{C}}$ & $G D_{20 \mathrm{C}} I_{20 \mathrm{C}}$ \\
\hline$T_{s}\left({ }^{\circ} \mathrm{C}\right)$ & 14.52 & 14.45 \\
Total cloud (\%) & 61.31 & 61.16 \\
Strat. cloud (\%) & 57.05 & 56.87 \\
Low cloud (\%) & 51.70 & 51.30 \\
TOA SW cloud forcing $\left(\mathrm{W} \mathrm{m}^{-2}\right)$ & -53.41 & -53.84 \\
LWP $\left(\mathrm{g} \mathrm{m}^{-2}\right)$ & 119.38 & 111.49 \\
Precip., $\left(\mathrm{mm} \mathrm{d}^{-1}\right)$ & 2.99 & 2.98 \\
Precip. (strat.) $\left(\mathrm{mm} \mathrm{d}^{-1}\right)$ & 0.96 & 0.93 \\
Surface SW flux $\left(\mathrm{W} \mathrm{m}^{-2}\right)$ & 161.98 & 162.83 \\
\hline
\end{tabular}

${ }^{\mathrm{a}} T_{s}$, surface temperature; SW, shortwave flux; CF, cloud forcing; LWP, liquid water path; precip., precipitation; strat., stratiform.

preindustrial level, 20C for year 2000 level, and 21C for year 2100 level.

[32] GHG forcing is imposed by fixing the concentrations of $\mathrm{CO}_{2}, \mathrm{CH}_{4}, \mathrm{~N}_{2} \mathrm{O}, \mathrm{CFC}-11$, and CFC-12 at specific levels; the values, based on IPCC SRES A2, are listed in the footnotes in Table 4. ADE forcing is imposed by the using the offline, monthly averaged aerosol mass concentrations from the fully coupled CACTUS Unified Model (sections 2.1 and 2.3.3). AIE forcing is imposed by using the offline, monthly averaged $N_{c}$ fields derived from the diagnostic formulation and aerosol soluble ion concentrations (section 2.2) to perturb cloud optical depth and liquid water (autoconversion). The 12 month, annual cycle of both aerosol mass and $N_{c}$ is repeated throughout the entire integration.

[33] The first two simulations were carried out to obtain a starting climate for the four key simulations. These two runs used the standard version of GISS III coupled with a Q-flux ocean that is consistent with the atmosphere of $20 \mathrm{C} \mathrm{GHG}$ levels and standard stratiform cloud scheme (i.e., without droplet-dependent cloud optical depth and autoconversion). These two 100 year simulations are (1) $G D_{20 c}$ : present-day equilibrium climate accounting for $\mathrm{GHG}$ and anthropogenic aerosol direct effect at present-day levels; and (2) $G D_{21 \mathrm{C}}$ : year 2100 equilibrium climate accounting for GHG and anthropogenic aerosol direct effect at year 2100 levels.

[34] The final year climate from the above simulations is used as the starting point for the following four AIE equilibrium climate runs. These 30 year simulations used the modified GCM with the droplet-dependent stratiform clouds and the consistent Q-flux ocean mentioned in section 2.3.2: (1) $G D_{20 \mathrm{C}} I_{20 \mathrm{C}}$ : present-day equilibrium climate accounting for GHG and anthropogenic aerosol direct and indirect effects at present-day levels (offline $N_{c}$ values corresponding to present-day aerosol levels); (2) $G D_{20 \mathrm{C}} I_{\mathrm{PI}}$ : equilibrium climate accounting for $\mathrm{GHG}$ and anthropogenic aerosol direct effect at present-day levels and aerosol indirect effects at preindustrial levels (offline $N_{c}$ values corresponding to preindustrial aerosol levels); (3) $G D_{20 \mathrm{C}} I_{21 \mathrm{C}}$ : equilibrium climate accounting for GHG and anthropogenic aerosol direct effect at present-day levels, and aerosol indirect effects at year 2100 levels (offline $N_{c}$ values corresponding to year 2100 aerosol levels); and (4) $G D_{21 \mathrm{C}} I_{21 \mathrm{C}}$ : year 2100 equilibrium climate accounting for $\mathrm{GHG}$, and anthropogenic aerosol direct and indirect effects at year 2100 levels (offline $N_{c}$ values corresponding to year 2100 aerosol levels).

[35] Statistics over the last 20 years of each of the above equilibrium climates are determined. Differences between the simulations are analyzed as follows: (1) $G D_{20 \mathrm{C}}$ versus $G D_{20 \mathrm{C}} I_{20 \mathrm{C}}$ : the effect of incorporating explicit dropletdependent autoconversion and optical depth and offline $N_{c}$ values on present-day equilibrium climate (section 5.1); (2) $G D_{20 \mathrm{C}} I_{20 \mathrm{C}}$ versus $G D_{20 \mathrm{C}} I_{\mathrm{PI}}$ : differences in equilibrium climate owing only to changes in $N_{c}$ between preindustrial and present day (section 5.2); (3) $G D_{20 \mathrm{C}} I_{21 \mathrm{C}}$ versus $G D_{20 \mathrm{C}} I_{20 \mathrm{C}}$ : differences in equilibrium climate owing only to changes in $N_{c}$ between present day and year 2100 (section 5.3); and (4) $G D_{21 \mathrm{C}} I_{21 \mathrm{C}}$ versus $G D_{20 \mathrm{C}} I_{20 \mathrm{C}}$ : differences in equilibrium climate between present day and year 2100 accounting for changes in GHG and anthropogenic aerosol direct and indirect effects (section 5.4).

[36] When differentiating each pair of the simulations, the two-sample "usual" $t$ test was applied to calculate the $95 \%$ confidence intervals [Zwiers and von Storch, 1995; Chen et

Table 6. Comparison of Global Annual Mean Cloud Properties in Present-Day Simulation $G D_{20 \mathrm{C}} I_{20 \mathrm{C}}$ With Remote Sensing Observations and Predictions in Selected GCM Studies

\begin{tabular}{|c|c|c|c|}
\hline & $G D_{20 \mathrm{C}} I_{20 \mathrm{C}}$ & Observation & Modeling Studies \\
\hline Total column $N_{c}^{\mathrm{a}}\left(10^{10} \mathrm{~m}^{-2}\right)$ & 6.16 & $4.4^{\mathrm{b}}$ & 2.1 to $7.6^{\mathrm{c}}$ \\
\hline$N_{c}$ at $850 \mathrm{hPa}\left(\mathrm{cm}^{-3}\right)$ & 122.22 & - & 75.0 to $135.0^{\mathrm{d}}$ \\
\hline \multirow[t]{2}{*}{$r_{e}$ at cloud top $\mathrm{e}^{\mathrm{e}}(\mu \mathrm{m})$} & (global) 12.18, (land) & (global) $11.4^{\mathrm{f}}$ and $14.7,^{\mathrm{g}}$ & (global) 6.8 to $11.3^{\mathrm{h}}$ \\
\hline & 9.26, (ocean) 13.10 & (land) $12.5,{ }^{\mathrm{g}}$ (ocean) $15.6^{\mathrm{g}}$ & \\
\hline $\operatorname{LWP}\left(\mathrm{g} \mathrm{m}^{-2}\right)$ & 111.49 & $93.3^{\mathrm{i}}$ & 41.5 to $110.0^{\mathrm{j}}$ \\
\hline TOA SW CF $\left(\mathrm{W} \mathrm{m}^{-2}\right)$ & -53.84 & $-50.0^{\mathrm{k}}$ & -49.9 to $-61.0^{1}$ \\
\hline
\end{tabular}

\footnotetext{
${ }^{\mathrm{a} A c c o u n t s}$ for cloudy periods in cloudy regions only.

${ }^{\mathrm{b}}$ Han et al. [1998] (International Satellite Cloud Climatology Project (ISCCP), average of January, April, July, and October 1987).

${ }^{\mathrm{c}}$ Menon et al. [2002] (GISS II with prescribed SST) and Hoose et al. [2008] (ECHAM5-HAM with in-cloud aerosol processing scheme and prescribed SST).

d Penner et al. [2006] (CAM-Oslo, LMD-Z, and CCSR with prescribed SST, in exp. 6).

${ }^{\mathrm{e}}$ Modeled values are multiplied by $2^{1 / 3}$ to approximate cloud top condition in the satellite retrievals.

${ }_{\mathrm{f}}$ Han et al. [1994] (ISCCP, average of January, April, July, and October 1987).

${ }^{\mathrm{g}}$ Meskhidze et al. [2007] (Moderate Resolution Imaging Spectroradiometer (MODIS), 2000 to 2006).

${ }^{\mathrm{h}}$ Menon et al. [2002], Kristjánsson et al. [2005] (CCM-Oslo with slab ocean, exp. ALLTOT), and Penner et al. [2006].

i Penner et al. [2006] (MODIS).

${ }^{\mathrm{j} K r i s t j a ́ n s s o n ~ e t ~ a l . ~[2005], ~ P e n n e r ~ e t ~ a l . ~[2006], ~ a n d ~ H o o s e ~ e t ~ a l . ~[2008] . ~}$

${ }^{\mathrm{k}}$ Kiehl and Trenberth [1997] (Earth Radiation Budget Experiment (ERBE), November 1984 through February 1990).

${ }^{1}$ Collins et al. [2006a] (CCSM3), Collins et al. [2006b] (CAM3), Penner et al. [2006], Hoose et al. [2008], and Kirkevåg et al. [2008b] (CAM-Oslo).
} 

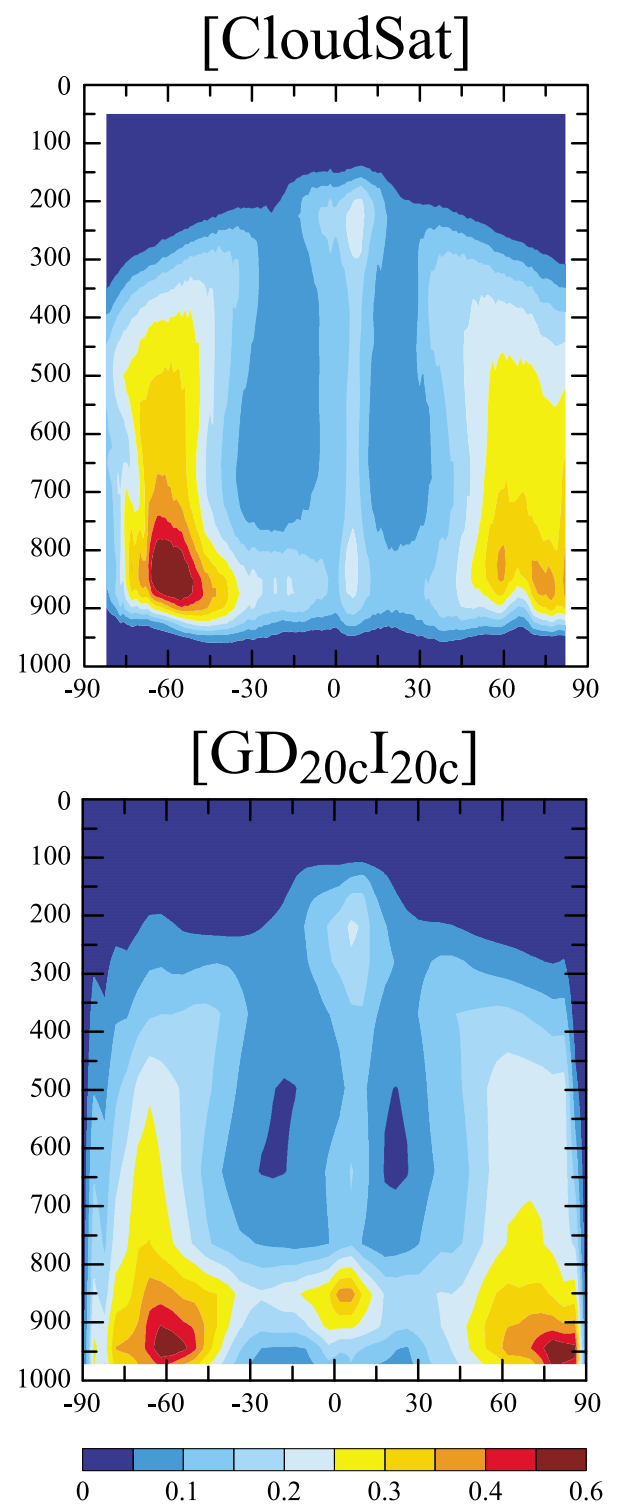

Figure 6. Zonal vertical distribution of present-day cloud frequency from (top) CloudSat observations (from July 2001 to August 2002) and (bottom) Goddard Institute for Space Studies (GISS) III general circulation model (GCM) prediction $\left(G D_{20 \mathrm{C}} I_{20 \mathrm{C}}\right.$, accounting for aerosol indirect effects).

al., 2007] (see Table 7, footnote). The results reported in sections 4 and 5 are statistically significant, unless otherwise explicitly noted.

\section{Responses of the Equilibrium Climate}

\subsection{Predicted Present-Day Equilibrium Climate}

[37] Comparing simulations $G D_{20 \mathrm{C}}$ versus $G D_{20 \mathrm{C}} I_{20 \mathrm{C}}$, it is found that (Table 5) replacement of the autoconversion scheme results in a smaller $(-4.1 \%)$ global annual mean LWP, which can be explained as follows. The offline, present-day $N_{c}$ values imposed on the modified model are, on average, higher than the constant values of $N_{c}$ implicitly assumed in the standard model in the calculation of cloud optical depth (section 2.3.1). Before replacing and tuning the autoconversion scheme, this change in $N_{c}$ fields alone causes the predicted stratiform clouds to be more reflective (results not shown). Since the new autoconversion scheme is tuned to match the overall TOA radiation balance simulated in the standard model (section 2.3.2), to compensate for the previous effect of higher $N_{c}$, the tuning eventually results in a lower LWP in the modified model. The modified GISS III also predicts a slightly cooler global mean surface temperature $(4.45 \mathrm{~K}$ versus $4.52 \mathrm{~K})$, less cloud cover, stronger (more negative) SW CF, and a more positive surface SW flux, whereas the predicted global mean precipitation rate is essentially identical between the standard and modified versions of GISS III.

[38] Several key cloud properties in the predicted presentday equilibrium climate with AIE-related processes $\left(G D_{20 \mathrm{C}} I_{20 \mathrm{C}}\right)$ are compared to satellite-retrieved climatology in Table 6 and Figures 6-8; the remote sensing instruments, observational periods, and related references are given in the footnotes for Table 6 and captions for Figures $6-8$. Note that
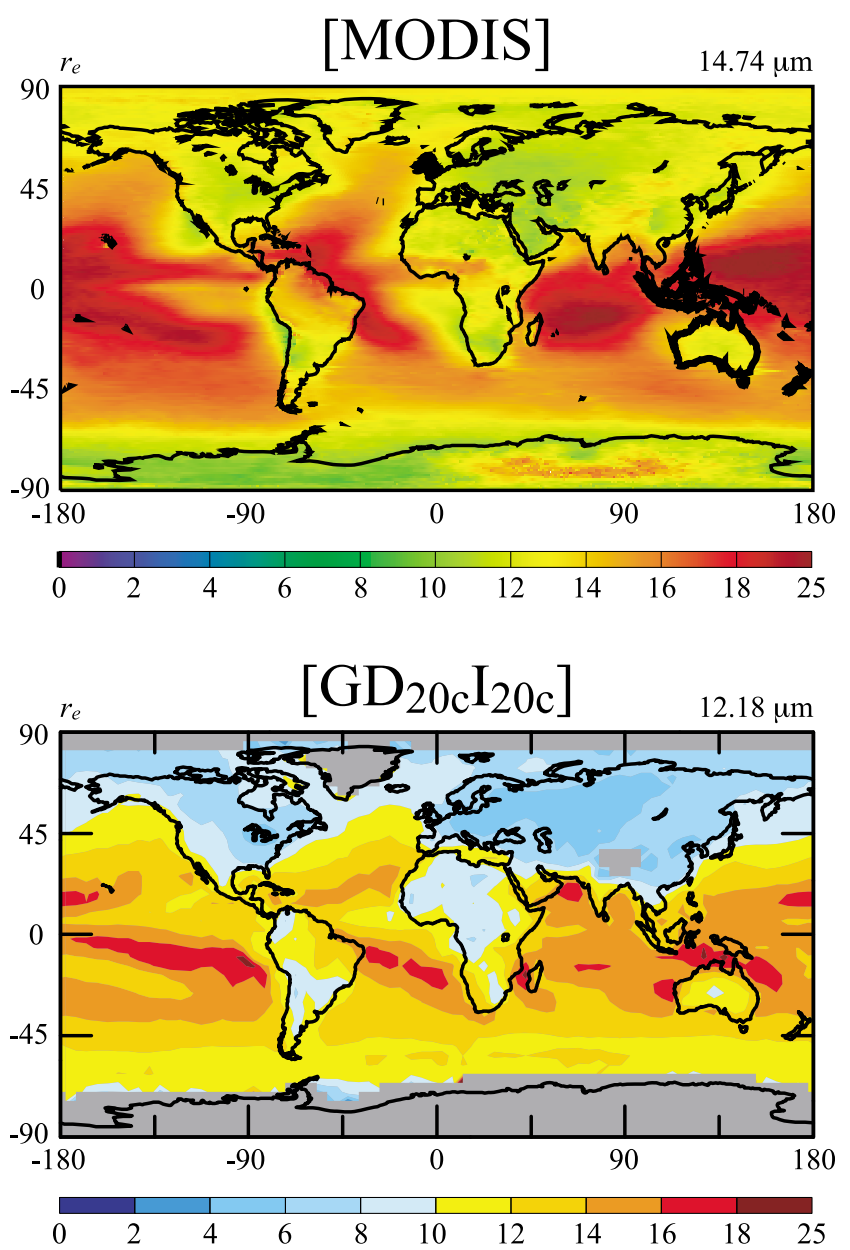

Figure 7. Present-day cloud droplet radius at warm cloud top from (top) Moderate Resolution Imaging Spectroradiometer (MODIS) retrievals (year 2000 to 2006) and (bottom) GISS III GCM prediction $\left(G D_{20 \mathrm{C}} I_{20 \mathrm{C}}\right.$, accounting for aerosol indirect effects). Global average values are given in the upper right corner of each plot. 


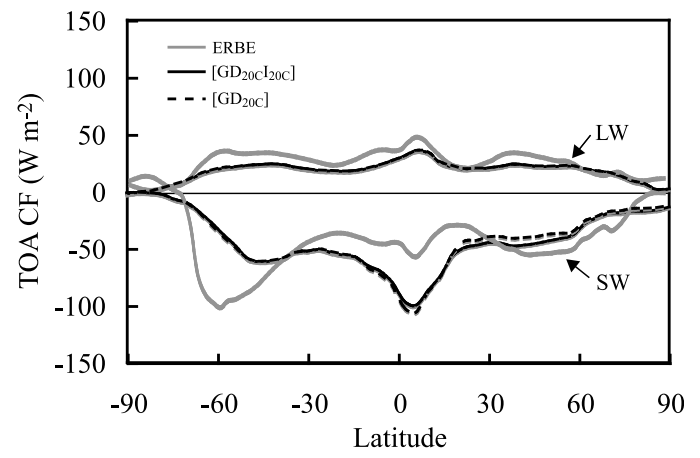

Figure 8. Zonal annual mean distribution of present-day top-of-atmosphere (TOA) shortwave (SW) and longwave (LW) cloud forcing (CF) observations from Earth Radiation Budget Experiment (ERBE) [Kiehl and Trenberth, 1997] (gray lines) and predicted in GISS III with AIE process $\left(G D_{20 \mathrm{C}} I_{20 \mathrm{C}}\right.$, black solid lines) and without AIE process ( $G D_{20 \mathrm{C}}$, black dashed lines).

exact agreement is not expected because of different time periods as well as the fact that the simulation is an equilibrium climate corresponding to present-day forcing, whereas the data reflect the actual transient climate. Also, the model data are sampled and summed at each time step (i.e., every $1 \mathrm{~h}$ for cloud microphysics; every $4 \mathrm{~h}$ for radiative properties), more frequently than the sampling of the satellite retrievals. Thus, the general latitudinal distributions of the variables are most relevant.

[39] Figure 6 compares the modeled present-day annual mean total cloud frequency zonal vertical profile (in $G D_{20 \mathrm{C}} I_{20 \mathrm{C}}$ ) with observation from the CloudSat cloud profiling radar (version 5.1, release 4 [RO4], August 2006 to July 2007). CloudSat measures the backscattered power using a $94 \mathrm{GHz}$, nadir-viewing radar to derive cloud and precipitation properties [Stephens et al., 2008]. The modified GISS III captures the general shape of the cloud frequency zonal vertical distribution, including the ITCZ over the tropics and the midlatitude storm tracks. For low-level liquid cloud, which is the focus in the present study, the altitude of peak cloud frequency at midlatitudes in GISS III locates around 950-900 $\mathrm{hPa}$ (the second and third model layers), lower than the peak altitude at $850 \mathrm{hPa}$ in the CloudSat observation (corresponding to the fourth model layer in GISS III). GISS III also overestimates the low cloud near the Tropics. The cloud frequency predicted in the standard GISS III $\left(G D_{20 \mathrm{C}}\right)$ is essentially identical to that in the modified model (not shown), implying the biases are not related to the modifications of the stratiform cloud scheme. The lower altitude of midlatitude liquid cloud frequency and overestimation of Tropical shallow clouds are commonly predicted in many GCMs (results not shown). These differences between the modeled and observed low-level cloud frequency may be related to the facts that (1) vertical resolution is different between GISS III (increasing from $200 \mathrm{~m}$ in the first layer to $600 \mathrm{~m}$ in the fourth layer) and CloudSat (250 m), (2) low cloud with tops below $1 \mathrm{~km}(\sim 900 \mathrm{hPa})$ are underrepresented in the CloudSat data, owing to radar clutter contamination from the surface [Stephens et al., 2008], and (3) the uncertainties in cloud parameterization, such as the relative humidity (RH) threshold for determining cloudiness in the RH-based stratiform cloud scheme in GISS GCM.

[40] Figure 7 compares the predicted global annual mean $r_{e}$ at warm cloud top in $G D_{20 \mathrm{C}} I_{20 \mathrm{C}}$ with the climatology retrieved by Moderate Resolution Imaging Spectroradiometer (MODIS Terra, Collection 005, Level-3, qualityassured pixel-weighted cloud properties averaged at $1^{\circ}$ by $1^{\circ}$ resolution; composites were made using monthly averages of available MODIS data from year 2000 to 2006 [Meskhidze et al., 2007; M. King et al., Collection 005 change summary for the MODIS cloud optical property (06-OD) algorithm, 2006, available at http://modis-atmos.gsfc.nasa.gov/products, C005update.html]) To ensure proper comparison with the satellite data, the predicted values at cloud top are taken and averaged over cloudy regions with cloud top temperature higher than $273 \mathrm{~K}$, with the cloud top defined as the highest GCM layer with liquid water content (LWC) $>10^{-9} \mathrm{~g} \mathrm{~m}^{-3}$ [Meskhidze et al., 2007]. Note that the $r_{e}$ in satellite retrieval represents the characteristic value at the cloud top, while the model value represents the average over the entire GCM layer in which the cloud top resides [Boucher and Lohmann, 1995; Quaas et al., 2004; Chen and Penner, 2005; Meskhidze et al., 2007]. To address this issue, we follow the treatment of Meskhidze et al. [2007] and multiply the modeled $r_{e}$ at cloud top by $2^{1 / 3}$, assuming that LWC varies linearly with height (i.e., LWC at the top $=2 x L W C$ averaged over the layer) and $N_{c}$ remains constant with height in the cloud top layer. This scaling to the modeled $r_{e}$ is applied here only for the comparison with satellite retrievals, but not in the climate simulations. As compared to MODIS data, GISS III simulates similar land-ocean contrast of $r_{e}$, with highest values over tropical Pacific owing to the conditions of low $N_{c}$ and high LWC, and lowest values over industrialized regions in China, western Europe and eastern United States owing to highly enhanced $N_{c}$. However, GISS III systematically underestimates $r_{e}$ by 2 to $3 \mu \mathrm{m}$ in both land and ocean areas, as summarized in Table 6 . Such biases are common in many present GCMs [Boucher and Lohmann, 1995; Quaas et al., 2004; Chen and Penner, 2005; Meskhidze et al., 2007], and are likely related to the uncertainties in the updraft velocity, liquid water content and its variability, and the cloud parameterization in the model, as well as the coarse model resolution and uncertainties in the retrieval algorithms.

[41] Figure 8 shows the zonal mean present-day shortwave and longwave TOA cloud forcing. While the predicted longwave (LW) $\mathrm{CF}$ matches well the observations of the Earth Radiation Budget Experiment (ERBE) [Kiehl and Trenberth, 1997], the model-derived SW CF exhibits a negative bias over the Tropics and a positive bias in midlatitudes to high latitudes in both hemispheres. Present-day cloud forcings predicted by modified GISS III $\left(G D_{20 \mathrm{C}} I_{20 \mathrm{C}}\right.$, black solid lines) are very similar to those in the standard GISS III ( $G D_{20 \mathrm{C}}$, black dashed lines), indicating the bias in $\mathrm{CF}$ is not associated with the AIE-related processes introduced in section 2.3.

[42] Table 6 lists the corresponding global mean values reported in several modeling studies focusing on AIE. Predictions of $N_{c}, r_{e}$, and $\mathrm{CF}$ in simulation $G D_{20 \mathrm{C}} I_{20 \mathrm{C}}$ generally fall within the range of previous studies. Although LWP is overestimated in the present work when compared to both 
(a)

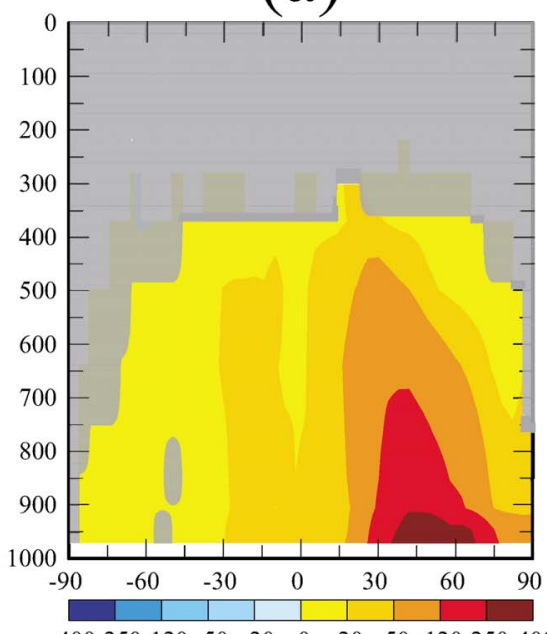

$-400-250-120-50 \quad-20 \quad 0 \quad 20 \quad 50 \quad 120 \quad 250 \quad 400-$

(d)

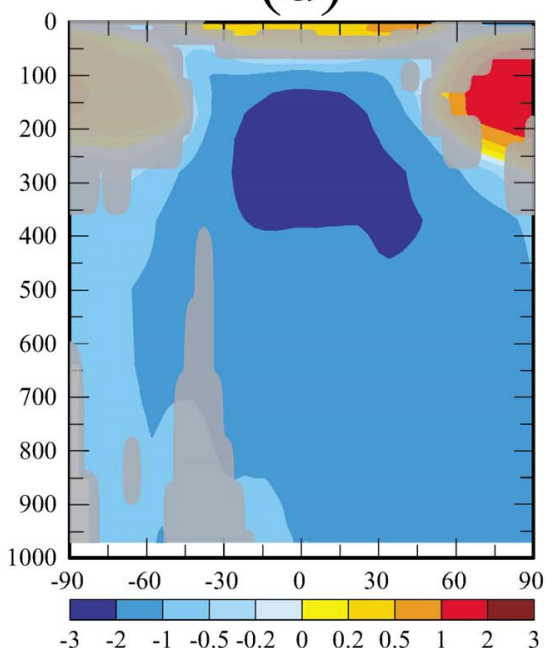

(g)

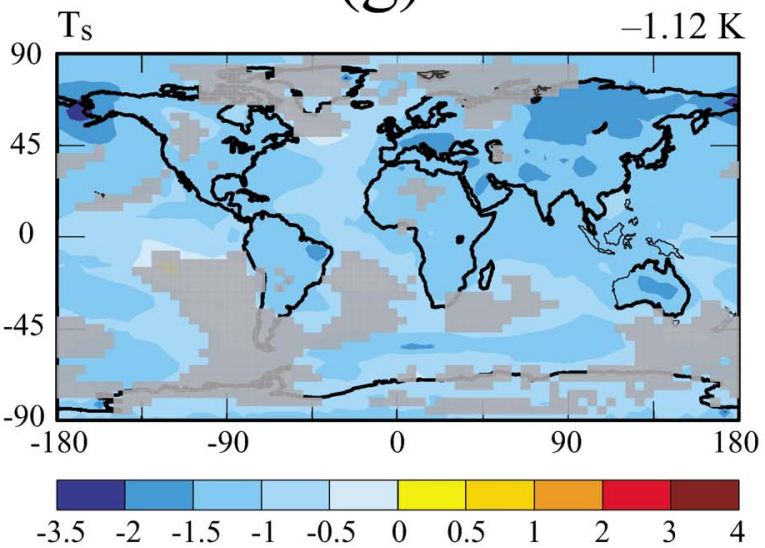

(b)

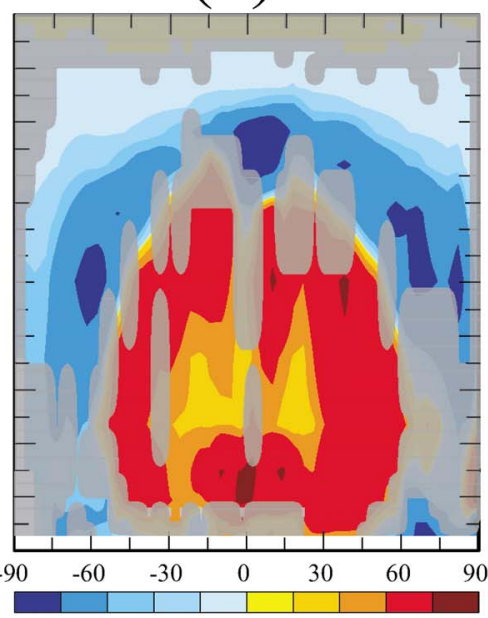

(e)
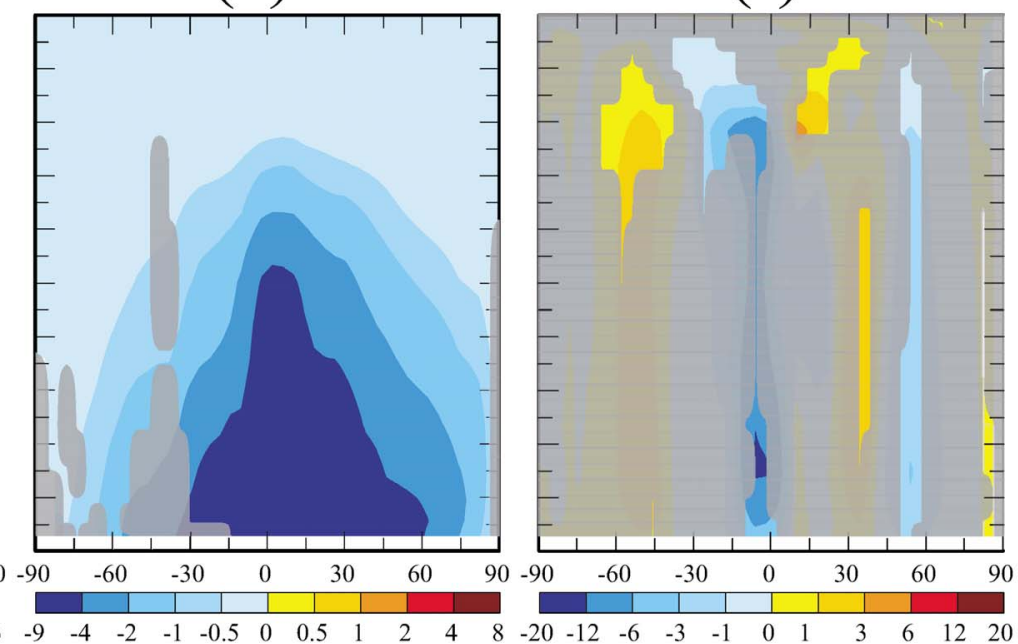

(h)

(c)

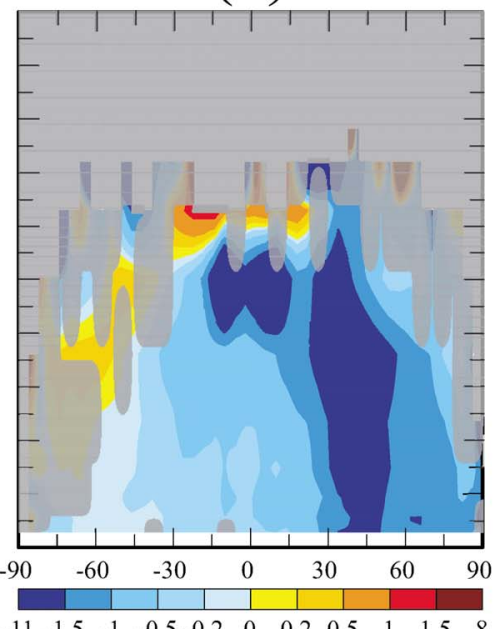

(f)

$-0.10 \mathrm{~mm} \mathrm{day}^{-1}$

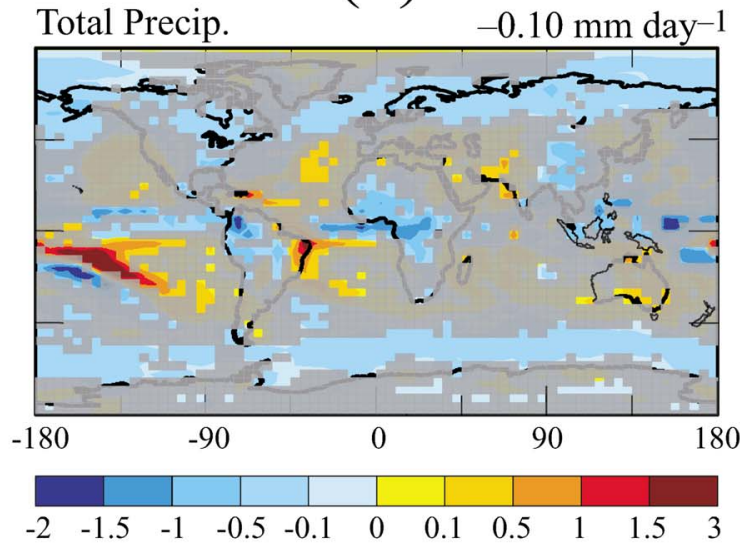

Figure 9. Present-day climate response to perturbation of AIE from preindustrial to present day $\left(G D_{20 \mathrm{C}} I_{20 \mathrm{C}}-G D_{20 \mathrm{C}} I_{\mathrm{PI}}\right)$ : vertical zonal profiles of changes in annual mean (a) $N_{c}$ in liquid stratiform clouds $\left(\mathrm{cm}^{-3}\right)$, (b) total cloud water mixing ratio $\left(10^{-6} \mathrm{~kg} \mathrm{H}_{2} \mathrm{O}(\mathrm{kg} \text { air })^{-1}\right)$, (c) $r_{e}$ in liquid stratiform clouds $(\mu \mathrm{m})$, (d) temperature $(\mathrm{K})$, (e) specific humidity $\left(10^{-4} \mathrm{~kg} \mathrm{H}_{2} \mathrm{O}\right.$ (kg air) ${ }^{-1}$ ), and (f) mass stream function $\left(10^{10} \mathrm{~kg} \mathrm{~s}^{-1}\right.$; positive values indicate counterclockwise flows); and annual mean changes in (g) $T_{s}(\mathrm{~K})$ and $(\mathrm{h})$ precipitation $\left(\mathrm{mm} \mathrm{d}^{-1}\right)$. Changes that are insignificant relative to the $95 \%$ confidence intervals are shaded. Global average values are given in the upper right corner of Figures $9 \mathrm{~g}$ and $9 \mathrm{~h}$. 

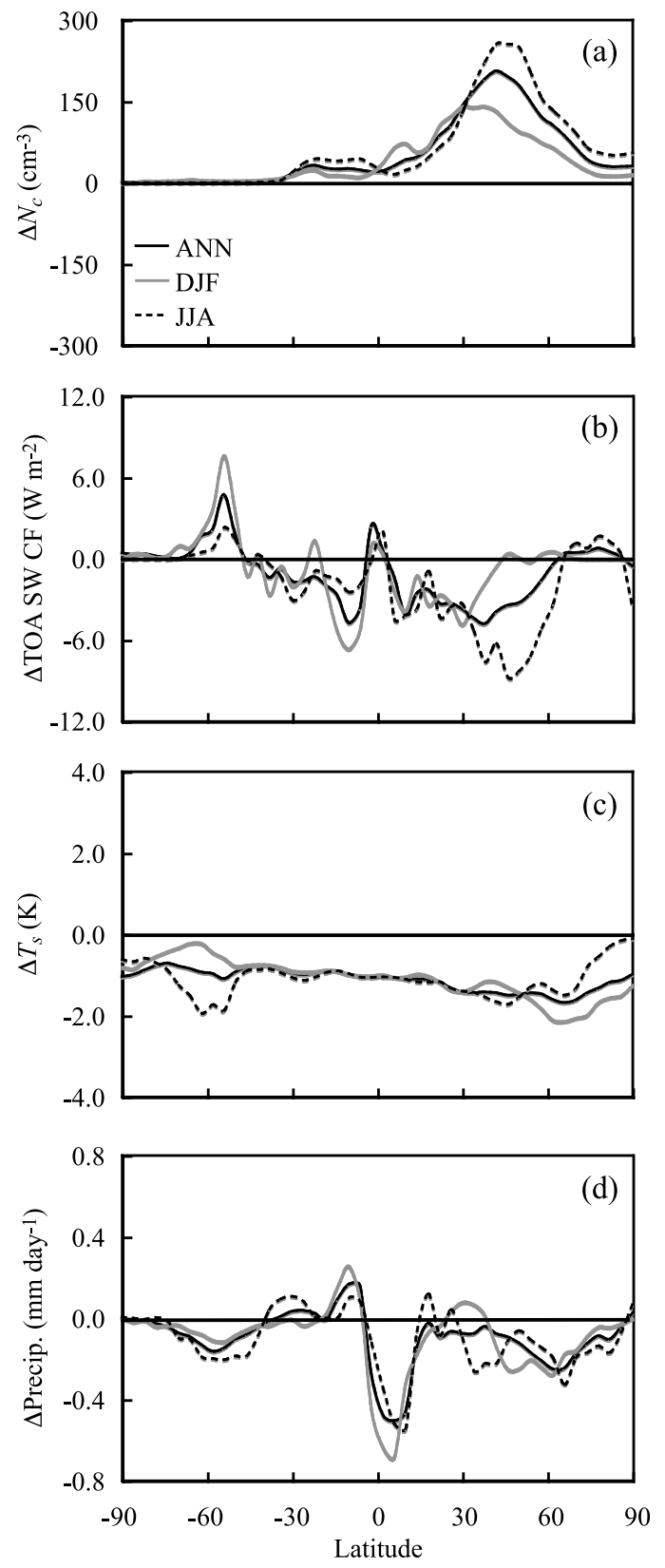

Figure 10. Present-day climate response to perturbation of AIE from preindustrial to present day $\left(G D_{20 \mathrm{C}} I_{20 \mathrm{C}}-\right.$ $\left.G D_{20 \mathrm{C}} I_{\mathrm{PI}}\right)$ : zonal mean changes in (a) $N_{c}$ at $850 \mathrm{hPa}\left(\mathrm{cm}^{-3}\right)$, (b) TOA SW CF $\left(\mathrm{W} \mathrm{m}^{-2}\right)$, (c) $T_{s}(\mathrm{~K})$, and (d) precipitation $\left(\mathrm{mm} \mathrm{d}^{-1}\right)$ (Black solid lines indicate annual average, gray lines indicate average over December-January-February (DJF), and dotted lines indicate average over June-JulyAugust (JJA)).

observation and previous predictions, one should note the uncertainties involved in the retrieval of this variable, the difference in cloud schemes and aerosol treatments used in various global models. Besides, from the simulations discussed subsequently, we find that the LWP in the GISS III is sensitive to temperature change, and increased/decreased LWP is always predicted when the model climate is warmed/cooled. The high bias of the present-day LWP can be explained partly by the fact that the simulated equilibrium climate is about $0.5 \mathrm{~K}$ warmer than the actual present-day climate [Jones et al., 1999], with the "warming commitment" of the GHG forcing not yet fully realized.

\subsection{Effects of Change of $N_{c}$ from Preindustrial to Present Day on Equilibrium Climate}

[43] In this section, the equilibrium climate response to the AIE perturbation from preindustrial to present day is analyzed, by comparing simulations $G D_{20 \mathrm{C}} I_{20 \mathrm{C}}$ and $G D_{20 \mathrm{C}} \mathrm{I}_{\mathrm{PI}}$. In both simulations, the GHG and ADE forcing are fixed at the present-day level, while offline $N_{c}$ fields for preindustrial and present-day conditions are imposed, respectively, in each simulation. The changes in key climate variables $\left(G D_{20 \mathrm{C}} I_{20 \mathrm{C}}-G D_{20 \mathrm{C}} I_{\mathrm{PI}}\right)$ are summarized in Figures 9 and 10 and the first column in Tables 7 and 8 .

[44] The maximum increase of $N_{c}$ in liquid stratiform clouds $\left(+100\right.$ to $\left.+400 \mathrm{~cm}^{-3}\right)$ is predicted to occur over 30 $60^{\circ} \mathrm{N}$, from the surface to $700 \mathrm{hPa}$, as shown in the latitudepressure profile in Figure 9a. The latitudinal distribution of changes in $N_{c}$ at $850 \mathrm{hPa}$ in Figure 10a reveals that the estimated increase in $N_{c}$ is more pronounced in June-JulyAugust (JJA, dotted line), and located at higher latitudes, than the increase in December-January-February (DJF, gray solid line). Over the region of maximal $N_{c}$ increase, autoconversion rates are predicted to decrease, which leads to increased liquid cloud water mixing ratio ( +1 to $+3 \mathrm{ppmm})$ in the low and midtroposphere in $\mathrm{NH}$, as shown in Figure $9 \mathrm{~b}$. For the change in droplet size, the effect of larger $N_{c}$ dominates that of increased cloud water, as the predicted $r_{e}$ in warm stratiform cloud decreases by more than $1 \mu \mathrm{m}$ (Figure 9c). Around $400 \mathrm{hPa}$ over the Tropics, the cloud droplet size is predicted to increase (Figure $9 \mathrm{c}, 0.2-1.5 \mu \mathrm{m}$ ), owing to the higher cloud water in stratiform clouds (not shown) and the relatively small change in $N_{c}$ estimated over this region. Note that pure liquid stratiform clouds do not frequently occur at this altitude over the Tropics, and therefore the impact of increasing droplet size should be small. The estimated change in cloud cover is small $(<2 \%$ of absolute amount in all latitudes) for both stratiform and convective clouds, and therefore is not shown.

[45] As a result of increased cloud optical depths associated with smaller droplet size and higher cloud water in warm stratiform clouds, negative changes in zonal mean TOA SW CF of up to $-5 \mathrm{~W} \mathrm{~m}^{-2}$ are predicted over $30-60^{\circ} \mathrm{N}$ (Figure 10b). The negative AIE forcing results in a predicted global cooling of $-1.12 \mathrm{~K}$ at the surface. Figures $9 \mathrm{~d}$ and $9 \mathrm{e}$ show that the predicted cooling leads to a decrease in atmospheric water vapor. The maximum cooling near the tropical tropopause is a result of vertical temperature convective adjustment toward the moist adiabatic lapse rate; the pattern is similar to the simulated global warming owing to increased GHG [Manabe and Wetherald, 1975], but with an opposite sign. As displayed in Figures $9 \mathrm{~g}$ and $10 \mathrm{c}$, the surface temperature is reduced more significantly in $\mathrm{NH}$ $(-1.46 \mathrm{~K})$ and over land $(-1.31 \mathrm{~K})$, with a prominent cooling over the northern middle to high latitudes. Over 30 $50^{\circ} \mathrm{N}$, the surface cooling is predicted to be more substantial in JJA; this is also the season of maximum $N_{c}$ increase and negative AIE forcing, indicating that the cooling is a direct response to perturbation of $N_{c}$. North of $50^{\circ} \mathrm{N}$, however, the most significant cooling is estimated to occur in DJF, when 
Table 7. Changes in Annual Mean Cloud Properties Between the Equilibrium Climates ${ }^{\mathrm{a}}$

\begin{tabular}{|c|c|c|c|c|}
\hline & Regions & $\begin{array}{c}G D_{20 \mathrm{C}} I_{20 \mathrm{C}}- \\
G D_{20 \mathrm{C}} I_{\mathrm{PI}}\end{array}$ & $\begin{array}{c}G D_{20 \mathrm{C}} I_{21 \mathrm{C}}- \\
G D_{20 \mathrm{C}} I_{20 \mathrm{C}}\end{array}$ & $\begin{array}{c}G D_{21 \mathrm{C}} I_{21 \mathrm{C}}- \\
G D_{20 \mathrm{C}} I_{20 \mathrm{C}}\end{array}$ \\
\hline \multirow{5}{*}{$\begin{array}{l}\Delta \text { column } N_{c} \\
\quad\left(10^{10} \mathrm{~m}^{-2}\right)\end{array}$} & Global & +2.96 & +1.53 & +1.80 \\
\hline & Ocean & +0.84 & +0.28 & +0.38 \\
\hline & Land & +9.68 & +5.64 & +6.18 \\
\hline & $\mathrm{NH}$ & +5.37 & +2.65 & +3.40 \\
\hline & SH & +0.58 & +0.49 & +0.21 \\
\hline \multirow{5}{*}{$\begin{array}{c}\Delta r_{e} \text { at cloud } \mathrm{t} \\
\operatorname{op}^{\mathrm{b}}(\mu \mathrm{m})\end{array}$} & Global & -0.78 & -0.27 & $(+0.05)$ \\
\hline & Ocean & -0.44 & -0.20 & +0.03 \\
\hline & Land & -1.84 & -0.50 & -0.06 \\
\hline & $\mathrm{NH}$ & -1.15 & -0.31 & -0.19 \\
\hline & SH & -0.40 & -0.23 & +0.20 \\
\hline \multirow[t]{5}{*}{$\Delta \mathrm{LWP}\left(\mathrm{g} \mathrm{m}^{-2}\right)$} & Global & -4.03 & -0.60 & +20.45 \\
\hline & Ocean & -4.73 & $(-0.19)$ & +22.26 \\
\hline & Land & -2.26 & -1.66 & +15.84 \\
\hline & $\mathrm{NH}$ & -6.46 & $(-1.03)$ & +24.00 \\
\hline & $\mathrm{SH}$ & -1.61 & $(-0.17)$ & +16.89 \\
\hline \multirow{5}{*}{$\begin{array}{c}\Delta \text { LWP (strat.) } \\
\left(\mathrm{g} \mathrm{m}^{-2}\right)\end{array}$} & Global & +1.50 & $(+0.24)$ & +2.93 \\
\hline & Ocean & +1.55 & +0.42 & +2.34 \\
\hline & Land & +1.44 & $(-0.25)$ & +4.57 \\
\hline & $\mathrm{NH}$ & +2.20 & $(+0.19)$ & +3.77 \\
\hline & $\mathrm{SH}$ & +0.79 & $(+0.27)$ & +2.10 \\
\hline \multirow{5}{*}{$\begin{array}{l}\Delta \text { strat. cloud } \\
\quad(\% \text { (absolute) })\end{array}$} & Global & +0.71 & +0.37 & -2.00 \\
\hline & Ocean & +0.61 & +0.40 & -1.96 \\
\hline & Land & +0.97 & $(+0.32)$ & -2.08 \\
\hline & $\mathrm{NH}$ & +0.63 & +0.34 & -1.66 \\
\hline & SH & +0.80 & +0.41 & -2.33 \\
\hline \multirow{5}{*}{$\begin{array}{c}\Delta \text { TOA SW CF } \\
\left(\mathrm{W} \mathrm{m}^{-2}\right)\end{array}$} & Global & -1.61 & -0.69 & -1.88 \\
\hline & Ocean & -1.42 & -0.88 & -1.72 \\
\hline & Land & -2.08 & $(-0.22)$ & -2.29 \\
\hline & $\mathrm{NH}$ & -2.48 & -0.94 & -2.35 \\
\hline & SH & $(-0.74)$ & $(-0.44)$ & -1.42 \\
\hline \multirow[t]{5}{*}{$\Delta$ net $C F\left(\mathrm{~W} \mathrm{~m}^{-2}\right)$} & Global & -1.48 & -0.62 & -2.18 \\
\hline & Ocean & -1.13 & -0.72 & -2.20 \\
\hline & Land & -2.37 & -0.39 & -2.14 \\
\hline & $\mathrm{NH}$ & -2.58 & -0.86 & -2.34 \\
\hline & SH & $(-0.39)$ & $(-0.39)$ & -2.03 \\
\hline
\end{tabular}

${ }^{\mathrm{a}}$ Differences insignificant relative to the $95 \%$ confidence intervals are parenthesized. The usual $t$ test takes into account the temporal correlation in each set of sample data (i.e., the global, land, ocean, or hemispherical annual average of the climate variable of interest in the last 20 years of each simulation). The sample sizes are reduced to the equivalent sample sizes $n_{e}$ and $m_{e}$. The $95 \%$ confidence interval equals to $1.98 \times s \times(1 /$ $\left.n_{e}+1 / m_{e}\right)^{0.5}$ if $n_{e}+m_{e} \geq 30$, where $s$ is the pooled standard deviation; for $n_{e}+m_{e}<30$, the interval is determined by a lookup table. For a more detailed explanation, please refer to Zwiers and von Storch [1995].

${ }^{b}$ Values reported here are not scaled by $2^{1 / 3}$ as in the model-satellite comparison.

the change in $N_{c}$ and TOA SW CF is relatively small. This pattern of predicted temperature response is similar to those found in previous studies investigating present-day AIE impacts [Rotstayn et al., 2000; Williams et al., 2001; Rotstayn and Lohmann, 2002; Kristjánsson et al., 2005].

[46] The amplification and the difference in the seasons of peak forcing and surface temperature in the northern high latitudes are likely related to ice-albedo feedback as well as feedback mechanisms involving sea ice, ocean-atmosphere heat exchange, and atmospheric dynamics, as analyzed by Williams et al. [2001] and Kristjánsson et al. [2005]. Note that the previous studies have predicted a more prominent polar amplification, which is likely associated with the difference in sea ice models, and the fact that aerosol concentrations were predicted interactively in those studies. However, considering the uncertainties in predicted sea ice and insufficient knowledge of the radiative impact of polar stratiform clouds, the actual mechanism of polar response to AIE requires more detailed studies [Garrett and Zhao, 2006].

[47] The predicted response in global circulation to surface cooling is a southward displacement of the ITCZ, which manifests itself by the change of distribution of precipitation in Figures $9 \mathrm{~h}$ and $10 \mathrm{~d}$. Figure $9 \mathrm{f}$ shows the changes in zonal mean mass stream function. The more substantial cooling in the $\mathrm{NH}$ induces a weak anomalous clockwise flow over the Tropics between $20^{\circ} \mathrm{S}$ and $20^{\circ} \mathrm{N}$, but is mostly statistically insignificant. In general, a slower hydrological cycle is predicted in response to the perturbation of $N_{c}$ from preindustrial to present day. Global annual mean precipitation is predicted to decrease by $0.10 \mathrm{~mm} \mathrm{~d}^{-1}$ $(3.36 \%)$, especially in $\mathrm{NH}\left(-0.19 \mathrm{~mm} \mathrm{~d}^{-1}\right)$. The predicted decrease in stratiform precipitation is only $0.01 \mathrm{~mm} \mathrm{~d}^{-1}$, and the precipitation reduction comes mostly from lower convective precipitation, owing to decreasing moisture in the atmosphere. The overall effects of all the feedbacks lead to an increase in global mean LWP in stratiform cloud $\left(+1.50 \mathrm{~g} \mathrm{~m}^{-2}\right)$ but a decrease in total LWP $\left(-4.03 \mathrm{~g} \mathrm{~m}^{-2}\right)$. The global mean change in TOA net $\mathrm{CF}$ is $-1.48 \mathrm{~W} \mathrm{~m}^{-2}$.

Table 8. Similar to Table 7, but for Changes in Annual Mean Temperature, Precipitation, Hydrological Sensitivity, and Surface Radiative Fluxes

\begin{tabular}{|c|c|c|c|c|}
\hline & Regions & $\begin{array}{c}G D_{20 \mathrm{C}} I_{20 \mathrm{C}}- \\
G D_{20 \mathrm{C}} I_{\mathrm{PI}}\end{array}$ & $\begin{array}{c}G D_{20 \mathrm{C}} I_{21 \mathrm{C}}- \\
G D_{20 \mathrm{C}} I_{20 \mathrm{C}}\end{array}$ & $\begin{array}{c}G D_{21 \mathrm{C}} I_{21 \mathrm{C}}- \\
G D_{20 \mathrm{C}} I_{20 \mathrm{C}}\end{array}$ \\
\hline \multirow[t]{5}{*}{$\Delta T_{s}(\mathrm{~K})$} & Global & -1.12 & -0.47 & +4.60 \\
\hline & Ocean & -0.99 & -0.43 & +4.20 \\
\hline & Land & -1.46 & -0.58 & +5.61 \\
\hline & $\mathrm{NH}$ & -1.31 & -0.47 & +4.63 \\
\hline & SH & $(-0.93)$ & -0.48 & +4.58 \\
\hline \multirow{5}{*}{$\begin{array}{l}\Delta \text { precip. } \\
\qquad\left(\mathrm{mm} \mathrm{d}^{-1}\right)\end{array}$} & Global & -0.10 & -0.05 & +0.26 \\
\hline & Ocean & -0.08 & -0.04 & +0.32 \\
\hline & Land & -0.16 & -0.09 & +0.12 \\
\hline & $\mathrm{NH}$ & -0.19 & -0.06 & +0.29 \\
\hline & SH & $(-0.02)$ & -0.04 & +0.23 \\
\hline \multirow{5}{*}{$\begin{array}{l}\Delta \text { precip. (strat.) } \\
\quad\left(\mathrm{mm} \mathrm{d}^{-1}\right)\end{array}$} & Global & -0.01 & -0.01 & -0.01 \\
\hline & Ocean & -0.01 & -0.01 & -0.02 \\
\hline & Land & -0.04 & -0.02 & +0.02 \\
\hline & $\mathrm{NH}$ & -0.01 & -0.01 & -0.03 \\
\hline & SH & $(-0.00)$ & -0.01 & +0.01 \\
\hline $\begin{array}{l}\Delta \text { precip./ } \Delta T_{s} \\
\quad\left(\% \mathrm{~K}^{-1}\right)\end{array}$ & Global & +3.00 & +3.57 & +1.90 \\
\hline \multirow{5}{*}{$\begin{array}{l}\Delta \text { surface } \mathrm{SW} \\
\quad \text { flux }\left(\mathrm{W} \mathrm{m}^{-2}\right)\end{array}$} & Global & -2.38 & -1.08 & +0.91 \\
\hline & Ocean & -1.90 & -1.07 & +0.91 \\
\hline & Land & -3.60 & -1.12 & +0.92 \\
\hline & NH & -2.93 & -1.06 & +0.44 \\
\hline & SH & -1.83 & -1.12 & +1.38 \\
\hline \multirow{5}{*}{$\begin{array}{l}\Delta \text { surface LW } \\
\quad \text { flux }\left(\mathrm{W} \mathrm{m}^{-2}\right)\end{array}$} & Global & -0.84 & -0.39 & +6.17 \\
\hline & Ocean & -1.22 & -0.53 & +7.12 \\
\hline & Land & $(+0.12)$ & $(-0.04)$ & +3.75 \\
\hline & NH & -1.00 & -0.39 & +6.02 \\
\hline & SH & -0.68 & -0.39 & +6.32 \\
\hline
\end{tabular}


(a)
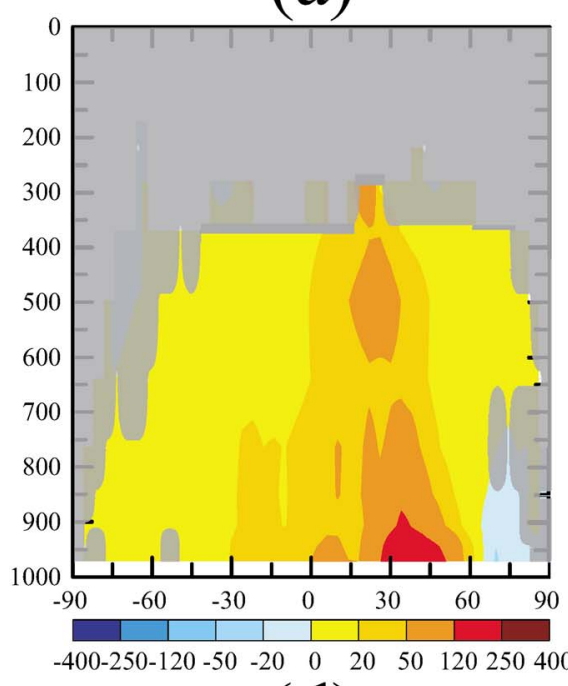

(d)

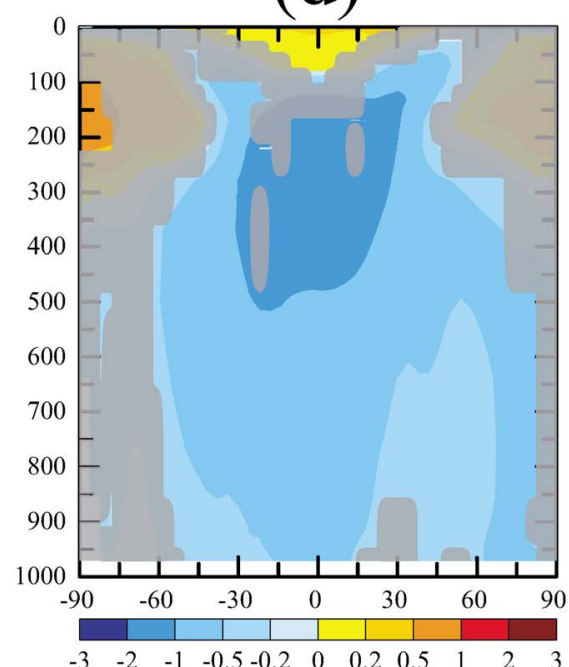

(g)

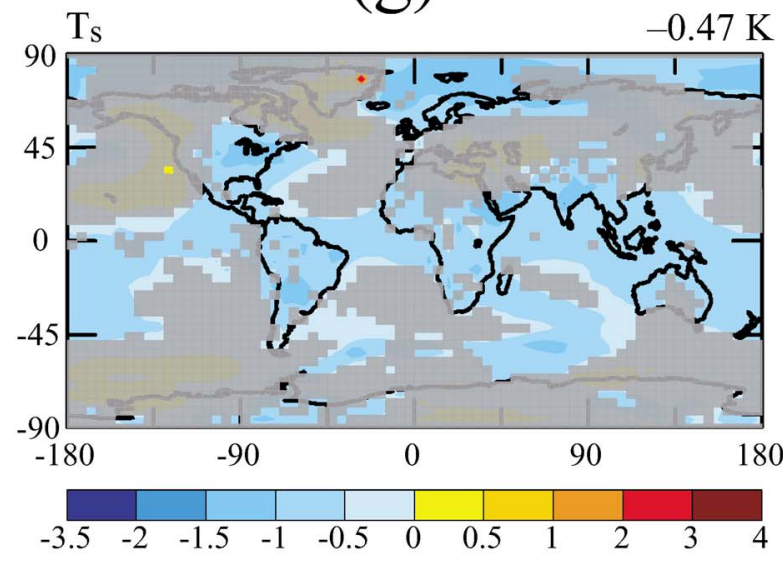

(b)

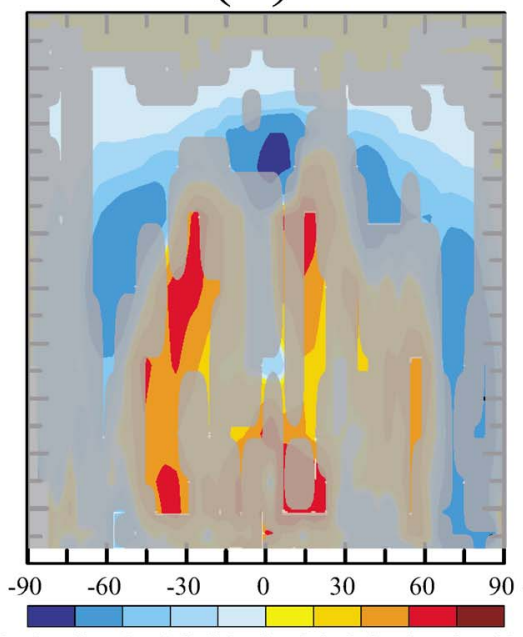

(e)

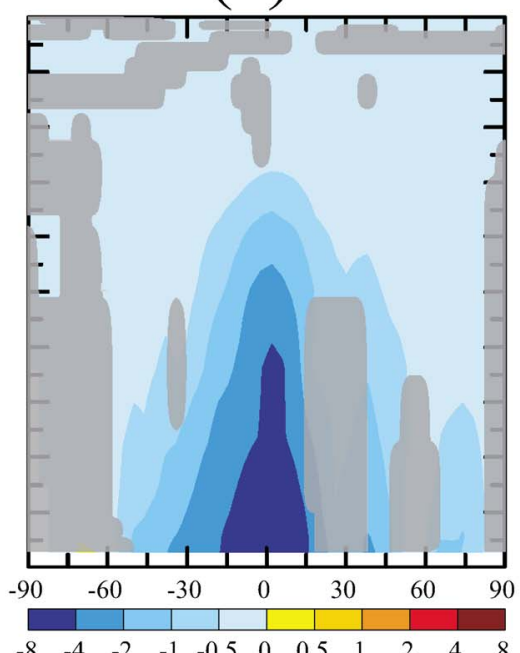

$\begin{array}{llllllllllll}8 & -20 & -12 & -6 & -3 & -1 & 0 & 1 & 3 & 6 & 12 & 20\end{array}$ (h)

(c)

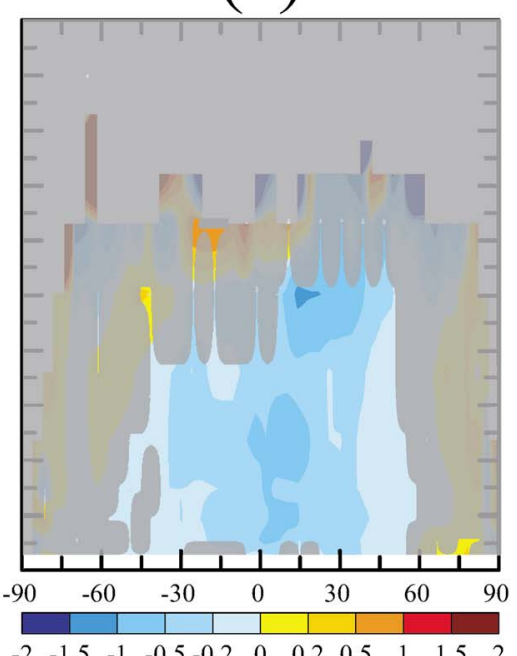

(f)

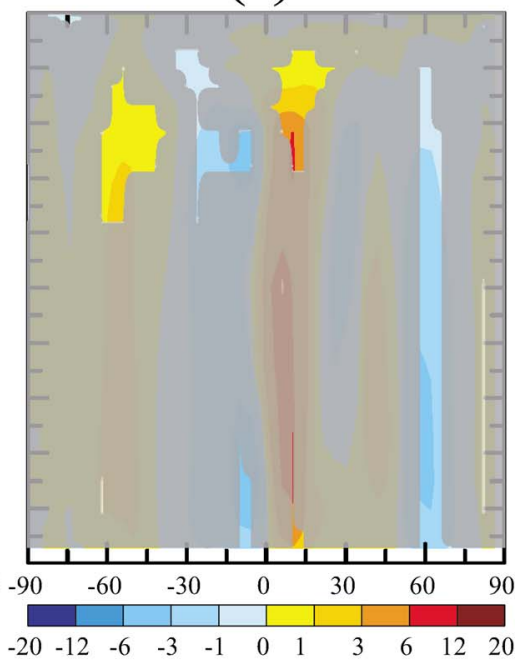

$-0.05 \mathrm{~mm} \mathrm{day}^{-1}$

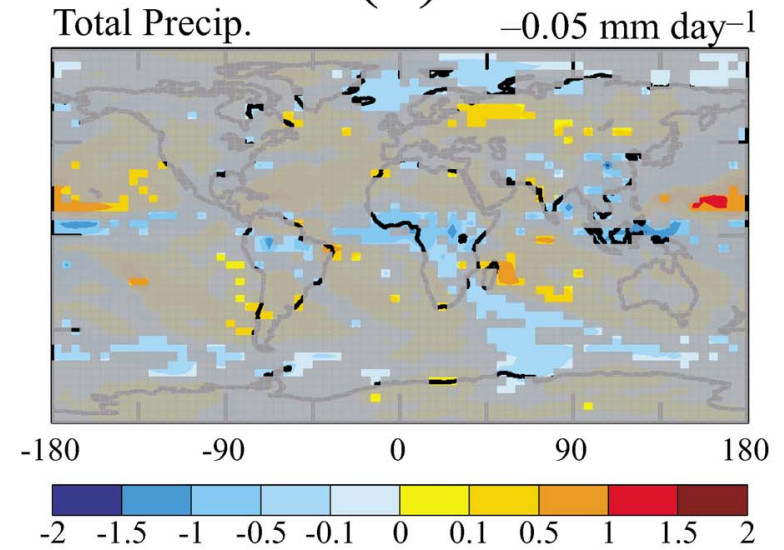

Figure 11. Similar to Figure 9 but for present-day climate response to perturbation of AIE from present day to year $2100\left(G D_{20 \mathrm{C}} I_{21 \mathrm{C}}-G D_{20 \mathrm{C}} I_{20 \mathrm{C}}\right)$. 

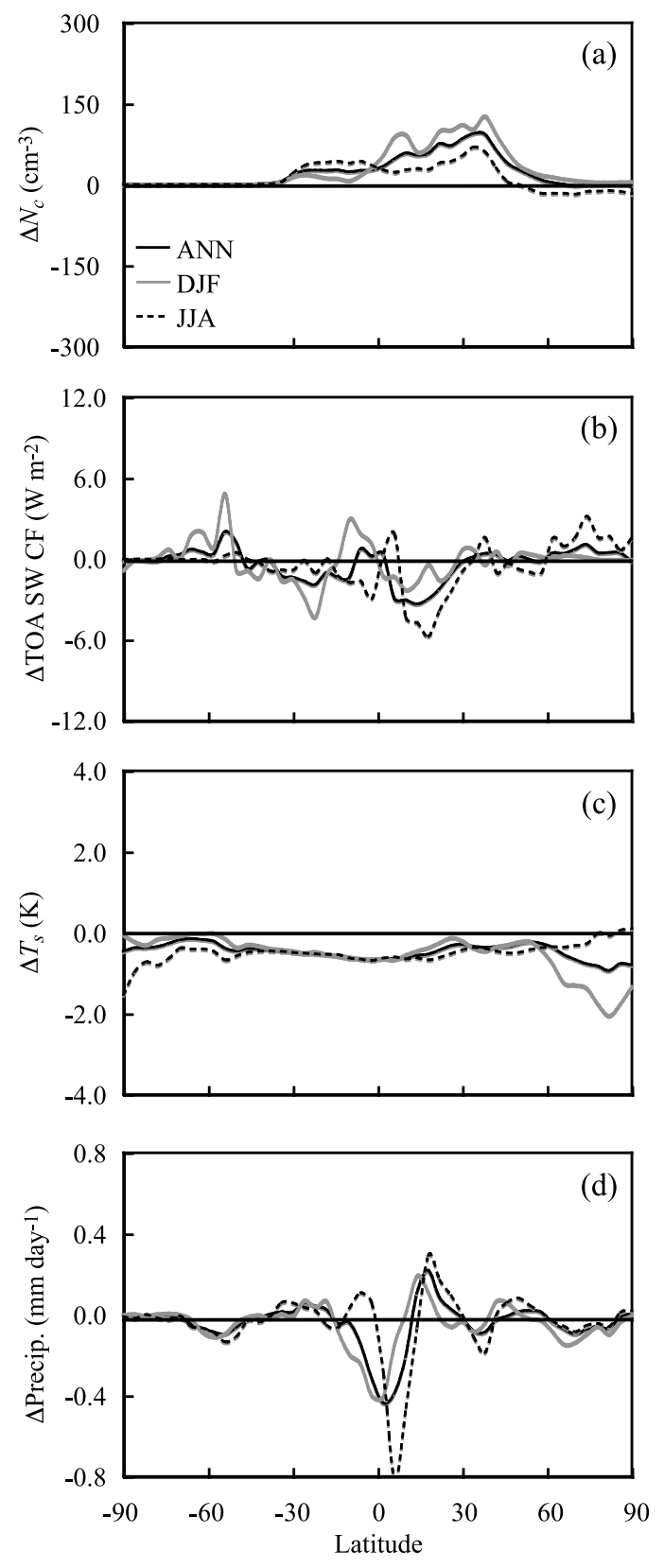

Figure 12. Similar to Figure 10 but for present-day climate response to perturbation of AIE from present day to year $2100\left(G D_{20 \mathrm{C}} I_{21 \mathrm{C}}-G D_{20 \mathrm{C}} I_{20 \mathrm{C}}\right)$.

\subsection{Perturbations of $N_{c}$ from Present Day to Year 2100 to Equilibrium Climate}

[48] The equilibrium climate response to the AIE perturbation from present day to year 2100 is diagnosed here, by comparing simulations $G D_{20 \mathrm{C}} I_{21 \mathrm{C}}$ and $G D_{20 \mathrm{C}} I_{20 \mathrm{C}}$. Presentday GHG and ADE forcings are used in both simulations, while the imposed $N_{c}$ values in each simulation are for present day and year 2100 , respectively. The results $\left(G D_{20 \mathrm{C}} I_{21 \mathrm{C}}-G D_{20 \mathrm{C}} I_{20 \mathrm{C}}\right)$ are presented in Figures 11 and 12 and the second column of Tables 7 and 8 .

[49] In NH, the predicted $N_{c}$ increase from present day to year 2100 is smaller than that from preindustrial to present day, and the interhemispheric contrast is not as great. Over
$\mathrm{NH}$ high latitudes, $N_{c}$ is predicted to slightly decrease ( -15 to $-20 \mathrm{~cm}^{-3}$ ) in JJA (Figures 11a and 12a), corresponding to the estimated reduction in sulfate aerosols in this region [Chen et al., 2007]. Also, the latitude of peak increase in $N_{c}$ is predicted to shift southward to $30^{\circ} \mathrm{N}$. The changes in $N_{c}$ in the lower troposphere lead to a slight increase in cloud water $(+0.1$ to $+0.5 \mathrm{ppmm})$ and a decrease in $r_{e}$ in warm stratiform clouds $(-0.2$ to $-0.5 \mu \mathrm{m})$ (Figures $11 \mathrm{~b}$ and $11 \mathrm{c})$. The response in cloud cover is, again, insensitive to the perturbation in $N_{c}$. The predicted global mean surface cooling is $-0.47 \mathrm{~K}$, with small cooling over low and midlatitudes and amplified cooling over the polar regions (Figures $11 \mathrm{~g}$ and 12c). Statistically significant cooling of -0.5 to $-1.0 \mathrm{~K}$ is predicted over $\mathrm{NH}$ continents in midlatitudes to high latitudes. The maximum cooling near the tropical tropopause associated with water vapor feedback is still evident.

[50] The response in general circulation to the pattern of predicted surface cooling is mostly insignificant. A similar southward displacement of the ITCZ is predicted, leading to a suppression in annual mean precipitation around the equator by as much as $0.4 \mathrm{~mm} \mathrm{~d}^{-1}$ (Figure $11 \mathrm{~h}$ and 12d). The predicted global mean precipitation reduction from present day to year 2100 is $0.05 \mathrm{~mm} \mathrm{~d}^{-1}(1.68 \%)$. The predicted global mean LWP also exhibits a decrease $\left(-0.60 \mathrm{~g} \mathrm{~m}^{-2}\right)$.

\subsection{Combined Effects of GHG, ADE, and AIE From Present Day to Year 2100 on Equilibrium Climate}

[51] The differences between the equilibrium climates $\left(G D_{21 \mathrm{C}} I_{21 \mathrm{C}}-G D_{20 \mathrm{C}} I_{20 \mathrm{C}}\right)$, revealing the response to the combined forcing of GHG, ADE, and AIE from present day to year 2100, are outlined in Figures 13 and 14 and the third column of Tables 7 and 8 . The changes in $N_{c}$ are similar to those in section 4.3 and hence not displayed. As expected, the general pattern of the response is largely dominated by the GHG-induced warming. The increase of equilibrium global surface temperature from present day to year 2100 is predicted to be $4.60 \mathrm{~K}$. The warming is prominently amplified in polar regions by snow and ice albedo feedback and near the tropical tropopause through moist adiabatic adjustment (Figures 13a, 13d, and 14a). A broadened and weakened Hadley cell is revealed in the predicted difference in mass stream function (Figure 13c). Global annual mean total precipitation is predicted to increase by $0.26 \mathrm{~mm} \mathrm{~d}^{-1}$. The latitudinal pattern of excess precipitation (total precipitation minus total evaporation) is enhanced (Figure 14b), owing to the effects of increasing water vapor (Figure 13b) and increasing poleward moisture transport (not shown), as discussed by Held and Soden [2006]. A poleward shift of the storm tracks is also predicted (not shown). The predicted change in Hadley circulation, excess precipitation, and storm track, are consistent qualitatively with the projected future climate in most of the IPCC Fourth Assessment Report (AR4) models in response to GHG induced warming [e.g., Mitas and Clement, 2005; Held and Soden, 2006; Meehl et al., 2007].

[52] It is of interest to compare this present day to year 2100 equilibrium climate response to that predicted by the standard version of GISS III (i.e., $\left[G D_{21 \mathrm{C}}-G D_{20 \mathrm{C}}\right]$ versus $\left.\left[G D_{21 \mathrm{C}} I_{21 \mathrm{C}}-G D_{20 \mathrm{C}} I_{20 \mathrm{C}}\right]\right)$. According to Table 9, the modified GISS III, which incorporates AIE-related stratiform clouds, predicts a slightly weaker warming $(4.60 \mathrm{~K}$ versus $4.85 \mathrm{~K})$, less precipitation increase $\left(0.26 \mathrm{~mm} \mathrm{~d}^{-1}\right.$ 
(a)

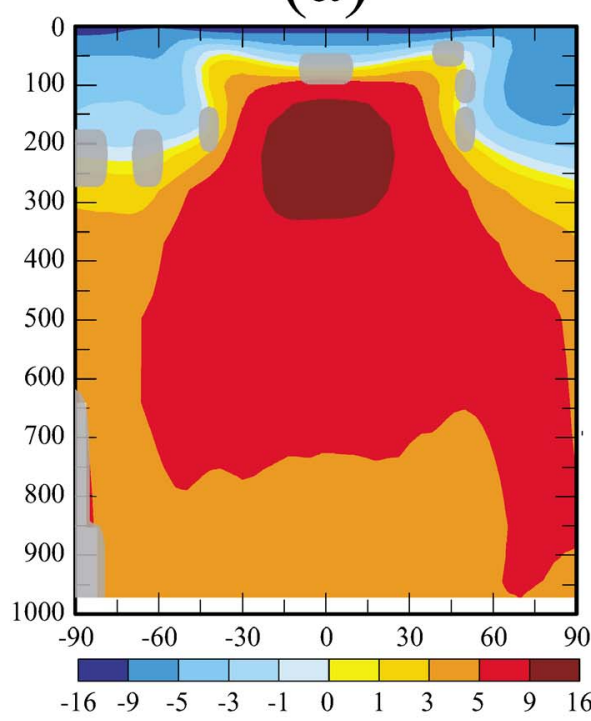

(d)

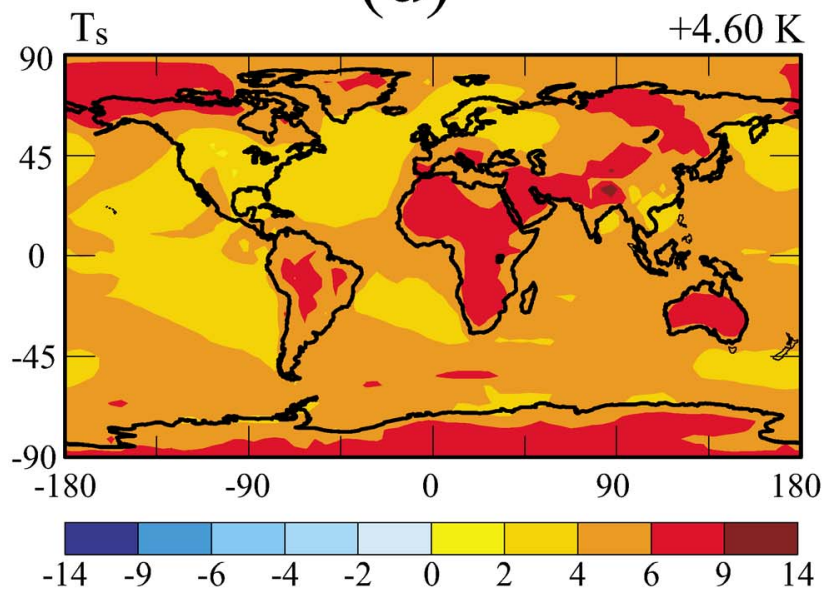

(b)

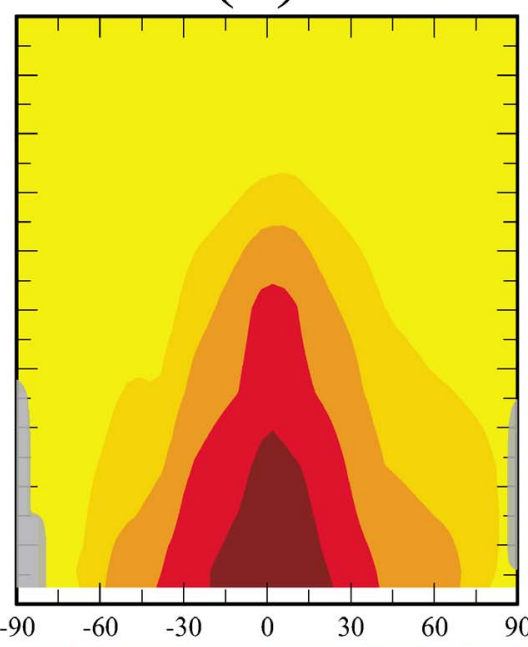

(c)

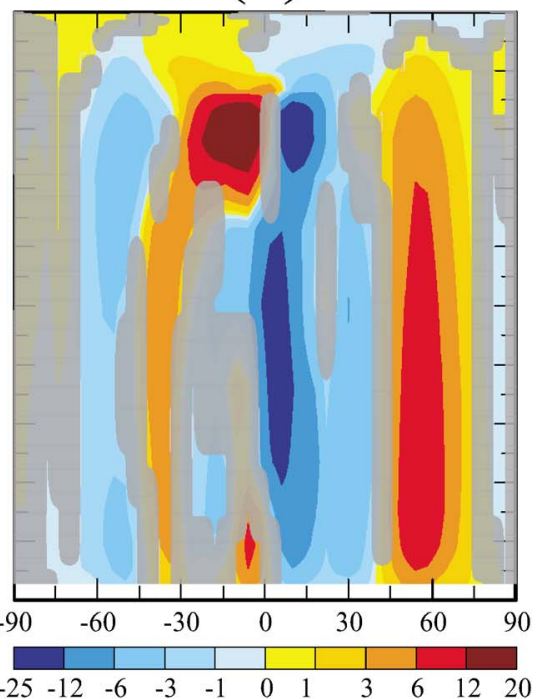

(e)

Total Precip.
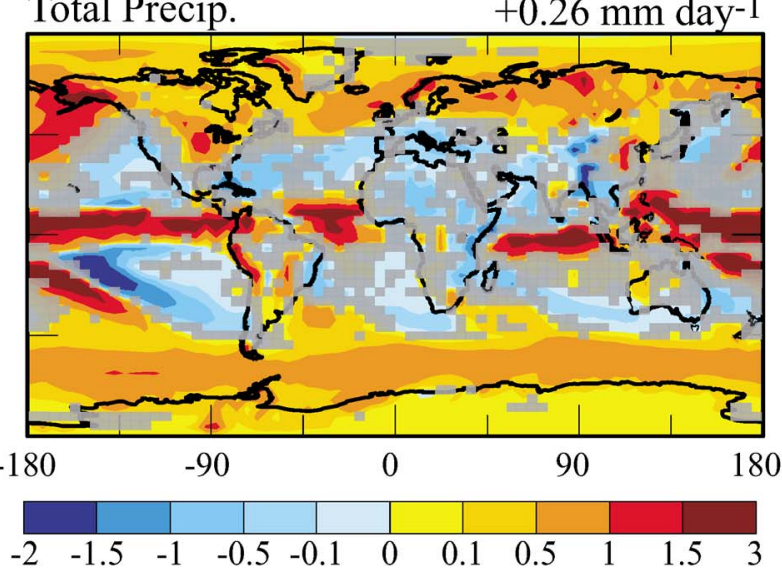

Figure 13. Climate responses to combined effects of greenhouse gas (GHG) and anthropogenic aerosol direct and indirect effects from present day to year $2100\left(G D_{21 \mathrm{C}} I_{21 \mathrm{C}}-G D_{20 \mathrm{C}} I_{20 \mathrm{C}}\right)$ : vertical zonal profiles of changes in annual mean (a) temperature $(\mathrm{K})$, (b) specific humidity $\left(10^{-4} \mathrm{~kg} \mathrm{H}_{2} \mathrm{O}\left(\mathrm{kg}\right.\right.$ air) $\left.{ }^{-1}\right)$, and (c) mass stream function $\left(10^{10} \mathrm{~kg} \mathrm{~s}^{-1}\right)$; annual mean changes in (d) $T_{s}(\mathrm{~K})$ and (e) precipitation $\left(\mathrm{mm} \mathrm{d}^{-1}\right)$. Global average values are given in the upper right corner of Figures $13 \mathrm{~d}$ and $13 \mathrm{e}$. Note the color scales are different from those of previous figures.

versus $\left.0.30 \mathrm{~mm} \mathrm{~d}^{-1}\right)$, and smaller reduction of absolute cloud cover $(-2.24 \%$ versus $-2.38 \%)$. The most pronounced difference between the predicted responses is the reversed sign in the change of stratiform cloud precipitation: $-0.01 \mathrm{~mm} \mathrm{~d}^{-1}$ in the modified GISS III versus $+0.05 \mathrm{~mm} \mathrm{~d}^{-1}$ in the standard GISS III. Figures $14 \mathrm{c}$ and $15 \mathrm{c}$ show that the standard model predicts minimal change of stratiform precipitation over Tropics and subtropics, in contrast to the predicted decrease of stratiform precipitation of 0.2 to $0.3 \mathrm{~mm} \mathrm{~d}^{-1}$ in the modified model over the same regions. This reveals the impact of the AIE on suppressing stratiform precipitation. The predicted latitudinal distributions of temperature, precipitation, and circulation changes are similar in both versions (Figures 14 and 15).

\subsection{Hydrological Sensitivities}

[53] The hydrological sensitivity is defined as the ratio of the percentage change in global total precipitation to the global surface temperature change. This section compares the hydrological sensitivity of AIE from $20 \mathrm{C}$ to $21 \mathrm{C}$ estimated in the current study with those reported in two related studies, Chen et al. [2007] and Liao et al. [2009] (Table 10), and in the literature. Chen et al. [2007] simulated the equilibrium climate response to $\mathrm{ADE}$ and $\mathrm{GHG}$ from present day to year 2100, based on SRES A2 scenario, using the 9 layer GISS II' GCM. The 20C and 21C offline aerosol fields used in that study are very similar to those in the present work (before interpolation from 9 to 23 vertical layers). Liao et al. [2009] performed fully coupled 

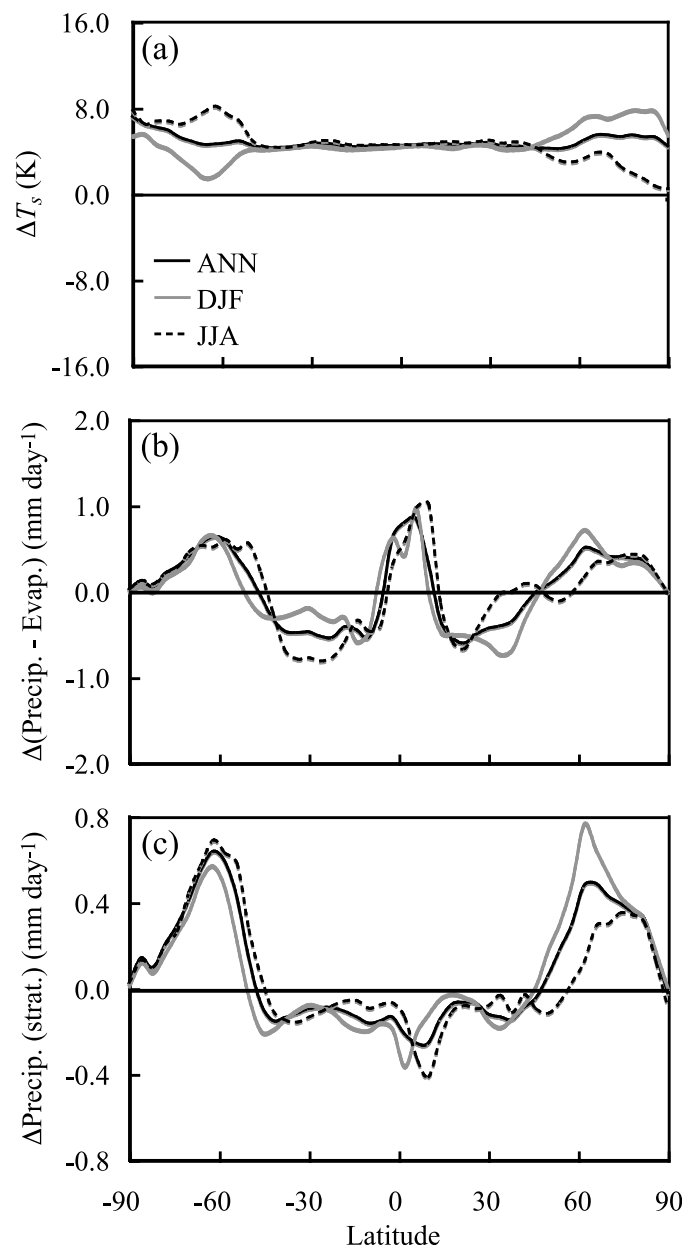

Figure 14. Climate responses to combined effects of GHG and anthropogenic aerosol direct and indirect effects from present day to year $2100\left(G D_{21 \mathrm{C}} I_{21 \mathrm{C}}-G D_{20 \mathrm{C}} I_{20 \mathrm{C}}\right)$ : zonal mean changes in (a) $T_{s}(\mathrm{~K})$, (b) excess precipitation (total precipitation minus evaporation, $\mathrm{mm} \mathrm{d}^{-1}$ ), and (c) precipitation from stratiform clouds $\left(\mathrm{mm} \mathrm{d}^{-1}\right)$. Black solid lines, annual (ANN) average; gray lines, DJF; and dashed lines, JJA.

chemistry-aerosol-climate simulations for present day and year 2100. Since the model physics, the length of integrations, and number of years for statistical analyses differ in these three studies, only qualitative comparisons are addressed below.

Table 9. Change in Global Annual Mean Values of Key Climate Variables Between the Present Day and Year 2100 Equilibrium Simulations, Predicted by the Modified and Standard Version of GISS III

\begin{tabular}{lcc}
\hline & $G D_{21 \mathrm{C}}-G D_{20 \mathrm{C}}$ & $G D_{21 \mathrm{C}} I_{21 \mathrm{C}}-G D_{20 \mathrm{C}} I_{20 \mathrm{C}}$ \\
\hline$\Delta T_{s}(\mathrm{~K})$ & +4.85 & +4.60 \\
$\Delta$ precip. (mm d & $-1)$ & +0.26 \\
$\Delta$ precip. (strat.) $\left(\mathrm{mm} \mathrm{d}^{-1}\right)$ & +0.30 & -0.01 \\
$\Delta$ precip./ $\Delta T_{s}\left(\% \mathrm{~K}^{-1}\right)$ & +0.05 & +1.90 \\
$\Delta$ total cloud $(\%$ (absolute) $)$ & +2.07 & -2.24 \\
$\Delta$ strat. cloud (\% (absolute)) & -2.38 & -2.00 \\
$\Delta$ net CF $\left(\mathrm{W} \mathrm{m}^{-2}\right)$ & -2.02 & -2.18 \\
$\Delta \mathrm{LWP}\left(\mathrm{g} \mathrm{m}^{-2}\right)$ & -0.79 & +20.45 \\
\hline
\end{tabular}
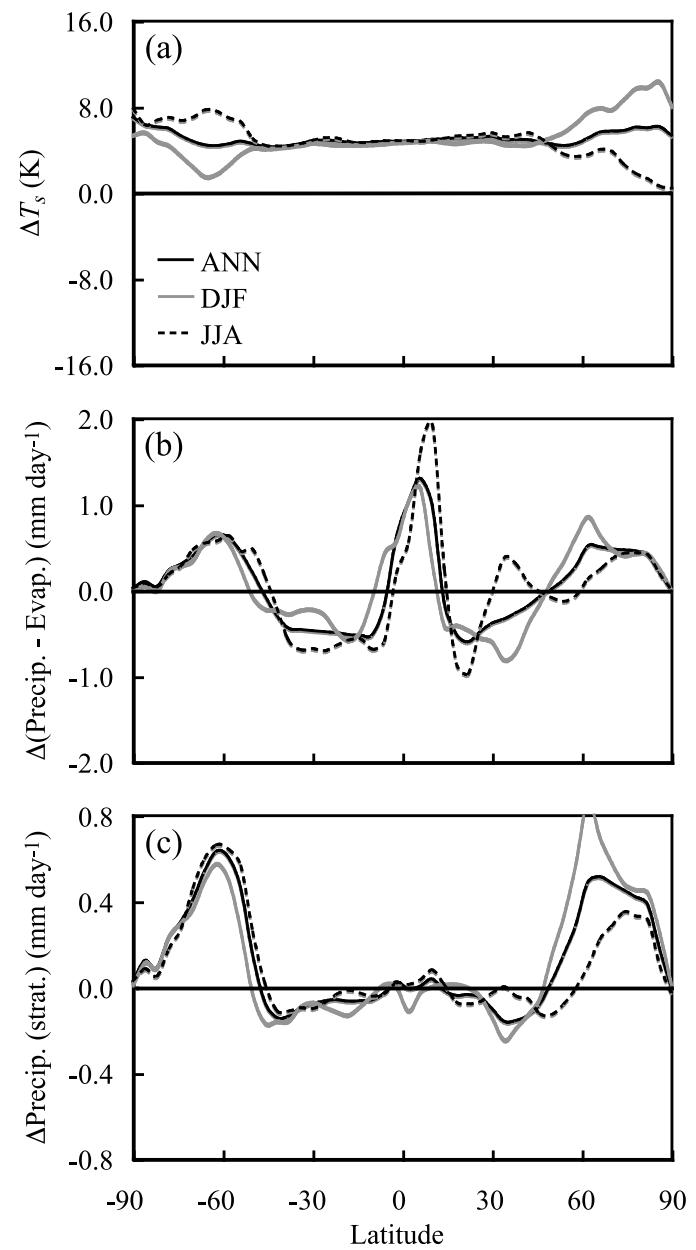

Figure 15. Similar to Figure 14, but for climate responses from present day to year 2100 predicted by the standard version of GISS III $\left(G D_{21 \mathrm{C}}-G D_{20 \mathrm{C}}\right)$.

[54] For the hydrological sensitivity of individual forcing, alone, the reported value GHG forcing is $2.19 \% \mathrm{~K}^{-1}$ in the work of Chen et al. [2007], as compared to $1.5 \% \mathrm{~K}^{-1}$ in the work of Feichter et al. [2004] (ECHAM4, GHG from PI to present day), and $1.8 \% \mathrm{~K}^{-1}$ in the work of Kirkevåg et al. [2008a] (CCM-Oslo, $\mathrm{CO}_{2}$ doubling). The hydrological sensitivity for ADE alone from $20 \mathrm{C}$ to $21 \mathrm{C}$ is $-7.34 \% \mathrm{~K}^{-1}$ in GISS GCM II', as reported by Chen et al. [2007]. The value is negative because the anthropogenic aerosols, including $\mathrm{BC}$, are assumed to be internally mixed. The absorbing aerosols are predicted to lead to a small global mean surface warming $(+0.14 \mathrm{~K})$, as regional warming by absorbing aerosols over reflective surfaces offsets the regional cooling by the increase of scattering aerosols. However, the associated global mean precipitation is slightly suppressed $(-1.03 \%)$, owing to the dominant effects of reduced evaporation and enhanced stability over regions exhibiting surface cooling. The hydrological sensitivity for AIE forcing reported in the present study is $3.00 \% \mathrm{~K}^{-1}$ from PI to $20 \mathrm{C}$ and $3.57 \% \mathrm{~K}^{-1}$ from $20 \mathrm{C}$ to $21 \mathrm{C}$ (Table 8 ).

[55] For combined GHG, ADE, and AIE forcing, the hydrological sensitivity in the present study is $1.90 \% \mathrm{~K}^{-1}$ for $20 \mathrm{C}$ to $21 \mathrm{C}$. The reported value is $-1.90 \% \mathrm{~K}^{-1}$ for PI to present day in the work of Feichter et al. [2004], and 0.30 or 
Table 10. Comparisons of Present Day to Year 2100 Hydrological Sensitivity Between the Present Study and Two Previous Related Studies

\begin{tabular}{|c|c|c|c|c|c|c|}
\hline Types of Forcing & GHG & $\mathrm{ADE}$ & $\mathrm{GHG}+\mathrm{ADE}$ & $\mathrm{GHG}+\mathrm{ADE}$ & AIE & $\mathrm{GHG}+\mathrm{ADE}+\mathrm{AIE}$ \\
\hline Study & $\begin{array}{c}\text { Chen et al. } \\
\text { [2007] }\end{array}$ & $\begin{array}{c}\text { Chen et al. } \\
\text { [2007] }\end{array}$ & Liao et al. [2009] & Present study & Present study & Present study \\
\hline GCM & GISS II' & GISS II' & $\begin{array}{l}\text { CACTUS unified } \\
\text { model (GISS II') }\end{array}$ & $\begin{array}{l}\text { Standard } \\
\text { GISS III }\end{array}$ & $\begin{array}{l}\text { Modified } \\
\text { GISS III }\end{array}$ & $\begin{array}{l}\text { Modified } \\
\text { GISS III }\end{array}$ \\
\hline $\begin{array}{l}\text { Predictions of aerosols and/or } \\
N_{c} \text { in the simulations }\end{array}$ & - & Offline & $\begin{array}{l}\text { Online with fully } \\
\text { coupled chemistry } \\
\text { and climate }\end{array}$ & Offline & Offline & Offline \\
\hline Integration (diagnostic period) (years) & 80 (last 30) & 80 (last 30) & 35 (last 20) & 100 (last 20) & $100+30$ (last 20) & $100+30$ (last 20) \\
\hline Equilibrium response of global $T_{s}(\mathrm{~K})$ & +5.31 & +0.14 & +6.00 & +4.85 & -0.47 & +4.60 \\
\hline Equilibrium response of global precip. (\%) & +11.64 & -1.03 & +9.00 & +10.03 & -1.68 & +8.72 \\
\hline Hydrological sensitivity $\left(\% \mathrm{~K}^{-1}\right)$ & +2.19 & -7.34 & +1.5 & +2.07 & +3.57 & +1.90 \\
\hline
\end{tabular}

$0.24 \% \mathrm{~K}^{-1}$ for a combined $2 \mathrm{XCO}_{2}$ and changed aerosol emissions from PI to present day or year 2100, respectively, in the work of Kirkevaig et al. [2008a]. In the multimodel ensemble average in the IPCC 2007 report [Meehl et al., 2007], considering transient response to GHG and all other forcings with the A2 scenario from $20 \mathrm{C}$ to $21 \mathrm{C}$, the hydrological sensitivity is $1.45 \% \mathrm{~K}^{-1}$. These very different values indicate high uncertainties associated with the hydrological processes in the model when the effects of aerosols and GHG are included simultaneously. Note that Feichter et al. [2004] and Kirkevåg et al. [2008a] both simulated full aerosol-cloud-climate interactions. The hydrological sensitivity may be highly sensitive to the degree of "coupling" in the model. For example, Liao et al. [2009] calculated the fully coupled response to ADE and GHG changes from $20 \mathrm{C}$ to $21 \mathrm{C}$ with the GISS GCM II' and derived a hydrological sensitivity of $1.5 \% \mathrm{~K}^{-1}$, smaller than that for GHG with offline ADE in the standard GISS III in the present study $\left(2.07 \% \mathrm{~K}^{-1}\right)$.

\section{Summary and Conclusions}

[56] To investigate the climatic impacts of aerosol indirect effects with GISS III GCM, explicit dependence on $N_{c}$ has been introduced to the formulations of optical depth and autoconversion rates for liquid stratiform clouds in the GCM, to account for both cloud albedo and lifetime effects. Fully coupled chemistry-aerosol-climate simulations with the CACTUS Unified Model have been carried out to obtain offline aerosol mass concentrations. Additionally, using simulations with the GISS-TOMAS microphysics model and the FN CCN activation parameterization, grid-by-grid correlations between aerosol soluble ion concentration and $N_{c}$ have been established. The diagnostic correlations have been applied to the aerosol mass predicted in the Unified Model to compute corresponding offline $N_{c}$ fields.

[57] Two 100 year simulations using the standard GISS III have been carried out, each with GHG and aerosol direct forcing from offline aerosol mass for present day or year 2100 , to provide starting climates for the four equilibrium climate simulations using the GISS III with AIE-related implementation, each integrated for 30 years. By imposing offline monthly averaged $N_{c}$ for PI, present day, and year 2100 in each simulation, the climate responses to the perturbations of $N_{c}$ have been analyzed. The general patterns of the climate responses are summarized below and in Table 11.

[58] The perturbation of $N_{c}$ from PI to 20C, of which the full AIE forcing is $-1.67 \mathrm{~W} \mathrm{~m}^{-2}$, is predicted to cause an equilibrium global surface cooling of $1.12 \mathrm{~K}$, with maximum cooling at the $\mathrm{NH}$ high latitudes. The predicted interhemispheric temperature gradient induces an anomalous general flow between $20^{\circ} \mathrm{S}$ and $20^{\circ} \mathrm{N}$, and a southward displacement of the ITCZ. The equilibrium global mean precipitation reduction is $0.10 \mathrm{~mm} \mathrm{~d}^{-1}$, with a corresponding hydrological sensitivity of $3.00 \% \mathrm{~K}^{-1}$. The results are consistent with previous GCM studies on preindustrial to present-day AIE forcing.

[59] The perturbation of $N_{c}$ from $20 \mathrm{C}$ to $21 \mathrm{C}$, which is weaker in magnitude and has different latitudinal distribution than that from PI to $20 \mathrm{C}$, results in a full AIE forcing of $-0.58 \mathrm{~W} \mathrm{~m}^{-2}$. A small decrease of $0.47 \mathrm{~K}$ in predicted

Table 11. Summary of Patterns of Equilibrium Climate Response in the Present Study ${ }^{\mathrm{a}}$

\begin{tabular}{|c|c|c|c|}
\hline & Perturbation of $N_{c}$ From PI to $20 \mathrm{C}$ & Perturbation of $N_{c}$ From $20 \mathrm{C}$ to $21 \mathrm{C}$ & $\begin{array}{c}\text { Perturbation of GHG, } \mathrm{ADE} \text { and } N_{c} \\
\text { From } 20 \mathrm{C} \text { to } 21 \mathrm{C}\end{array}$ \\
\hline Change in $N_{c}$ & $\begin{array}{c}\text { Increase globally with maxima } \\
\text { over } 30-60^{\circ} \mathrm{N}\end{array}$ & $\begin{array}{l}\text { Maximum of increase over } 15-45^{\circ} \mathrm{N} \text {; } \\
\text { slight decrease north of } 60^{\circ} \mathrm{N} \text { in JJA }\end{array}$ & $\begin{array}{l}\text { Maximum of increase over } 15-45^{\circ} \mathrm{N} \\
\text { slight decrease north of } 60^{\circ} \mathrm{N} \text { in JJA }\end{array}$ \\
\hline Surface temperature & $\begin{array}{l}\text { Cooling globally, with amplification } \\
\text { especially at NH high lat. }\end{array}$ & $\begin{array}{l}\text { Small cooling over the Tropics and } \\
\text { subtropics; polar amplified }\end{array}$ & Warming globally with polar amplification \\
\hline General circulation & $\begin{array}{l}\text { Weak clockwise flow over the } \\
\text { Tropics; southward shift of ITCZ }\end{array}$ & $\begin{array}{l}\text { Weak clockwise flow over the Tropics; } \\
\text { southward shift of ITCZ }\end{array}$ & $\begin{array}{l}\text { Broadened Hadley Cell; strengthened } \\
\text { ascending branches in convection zone }\end{array}$ \\
\hline Precipitation & $\begin{array}{c}\text { Reduced global average; maximum } \\
\text { decrease over the Tropics; slightly } \\
\text { enhanced around } 15^{\circ} \mathrm{S}\end{array}$ & $\begin{array}{l}\text { Slightly reduced global average; } \\
\text { maximum decrease over the Tropics; }\end{array}$ & $\begin{array}{c}\text { Enhanced global average with maximum } \\
\text { at Equator; decreased stratiform } \\
\text { precipitation over } 45^{\circ} \mathrm{S} \text { to } 45^{\circ} \mathrm{N}\end{array}$ \\
\hline
\end{tabular}

${ }^{\mathrm{a} J J A}$, June-July-August. 
global surface temperature, with small interhemispheric contrast, and a weak response in precipitation and general circulation is predicted. The location of the ITCZ does not show a significant shift. The hydrological sensitivity has a similar value of $3.57 \% \mathrm{~K}^{-1}$, despite the AIE forcing is much smaller than that from PI to $20 \mathrm{C}$, indicating that the response of the hydrological cycle to AIE forcing in GISS III is likely characterized by a value of sensitivity larger than 3.0.

[60] In general, the simulated equilibrium climate response to the combined forcing of GHG, ADE, and AIE from present day to year 2100 , dominated by GHG warming effects, agrees with previous GCM studies, with a global temperature increase of $4.60 \mathrm{~K}$, maximized warming in polar regions and the tropical tropopause, broadened Hadley cell, and enhanced precipitation in the tropical convection zone and midlatitudes to high latitudes. The inclusion of AIE-related processes in the modified version of GISS III leads to a decrease in predicted stratiform precipitation and a hydrological sensitivity of $1.90 \% \mathrm{~K}^{-1}$, as compared to the increase in stratiform precipitation and the higher hydrological sensitivity of $2.07 \% \mathrm{~K}^{-1}$ predicted by the standard model.

[61] On the basis of the sensitivity calculation of the AIE forcing to the assumption of minimum $N_{c}$ values, when a smaller minimum $N_{c}$ is used, the present-day AIE forcing only changes slightly, whereas the future AIE forcing is enhanced by $12 \%$. This sensitivity indicates the climate responses predicted in the present study would be robust for AIE from PI to 20C, while those for AIE from 20C to 21C would be enhanced/decreased, given a smaller/larger value of minimum $N_{c}$.

[62] Finally, we note that the indirect effects on ice clouds and convective clouds are not considered in the present study. In addition, offline aerosols and droplet number concentrations have been used. Although the aerosol mass was derived by the fully coupled model, in the equilibrium climate calculations, feedbacks of temperature, precipitation, cloud, and transport on distribution of aerosol and droplet number were not accounted for. Evaluating the full indirect effects and the full coupling between tropospheric chemistry, aerosols, clouds, and climate is worthy of a future study.

[63] Acknowledgments. The authors would like to thank Nicholas Meskhidze and Rafaella Sotiropoulou for providing the MODIS data set and Jefferey Jonas for assisting the computation of Q-flux fields. This work was supported by the National Aeronautics and Space Administration (NASA) Earth Observing System Interdisciplinary Science Program (EOS-IDS) and NASA grant NNX08AL85G. Athanasios Nenes acknowledges support from a NASA New Investigator Award. Hong Liao was supported by National Natural Science Foundation of China (grants 90711004 and 40775083) and by National Basic Research Program of China (grant 2006CB403706).

\section{References}

Adams, P. J., and J. H. Seinfeld (2002), Predicting global aerosol size distributions in general circulation models, J. Geophys. Res., 107(D19), 4370, doi:10.1029/2001JD001010.

Asa-Awuku, A., A. Nenes, A. P. Sullivan, C. J. Hennigan, and R. J. Weber (2008), Investigation of molar volume and surfactant characteristics of water-soluble organic compounds in biomass burning aerosol, Atmos. Chem. Phys., 8, 799-812.
Asa-Awuku, A., G. J. Engelhart, B. H. Lee, S. N. Pandis, and A. Nenes (2009), Relating CCN activity, volatility, and droplet growth kinetics of beta-caryophyllene secondary organic aerosol, Atmos. Chem. Phys., 9, 795-812.

Bennartz, R. (2007), Global assessment of marine boundary layer cloud droplet number concentration from satellite, J. Geophys. Res., D02201, 112, doi:10.1029/2006JD007547.

Boucher, O., and U. Lohmann (1995), The sulfate-CCN-cloud albedo effect: A sensitivity study with two general circulation models, Tellus, Ser. B, 47, 281-300, doi:10.1034/j.1600-0889.47.issue3.1.x.

Bougiatioti, A., C. Fountoukis, N. Kalivitis, S. N. Pandis, A. Nenes, and N. Mihalopoulos (2009), Cloud condensation nuclei measurements in the eastern Mediterranean marine boundary layer: $\mathrm{CCN}$ closure and droplet growth kinetics, Atmos. Chem. Phys. Discuss., 9, 10,303-10,336.

Chen, W.-T., H. Liao, and J. H. Seinfeld (2007), Future climate impacts of direct radiative forcing of anthropogenic aerosols, tropospheric ozone, and long-lived greenhouse gases, J. Geophys. Res., 112, D14209, doi:10.1029/2006JD008051.

Chen, Y., and J. E. Penner (2005), Uncertainty analysis for estimates of the first indirect effect, Atmos. Chem. Phys., 5, 2935-2948.

Chung, S. H., and J. H. Seinfeld (2002), Global distribution and climate forcing of carbonaceous aerosols, J. Geophys. Res., 107(D19), 4407, doi:10.1029/2001JD001397.

Chung, S. H., and J. H. Seinfeld (2005), Climate response of direct radiative forcing of anthropogenic black carbon, J. Geophys. Res., 110, D11102, doi:10.1029/2004JD005441.

Collins, W. D., et al. (2006a), The Community Climate System Model Version 3(CCSM3), J. Clim., 19, 2122-2143, doi:10.1175/JCLI3761.1.

Collins, W. D., et al. (2006b), The formulation and atmospheric simulation of the Community Atmospheric Model Version 3 (CAM3), J. Clim., 19, 2144-2161, doi:10.1175/JCLI3760.1.

d'Almeida, G. A., P. Koepke, and E. P. Shettle (1991), Atmospheric Aerosol: Global Climatology and Radiative Characteristics, A. Deepak, Hampton, Va.

Del Genio, A. D., M.-S. Yao, W. Kovari, and K. K.-W. Lo (1996), A prognostic cloud water parameterization for global climate models, J. Clim., 9(2), 270-304, doi:10.1175/1520-0442(1996)009<0270 APCWPF $>2.0 . \mathrm{CO} ; 2$

Denman, K. L., et al. (2007), Couplings Between Changes in the Climate System and Biogeochemistry, edited by S. Solomon et al., Cambridge Univ. Press, Cambridge, U. K.

Dinar, E., I. Taraniuk, E. R. Graber, S. Katsman, T. Moise, T. Anttila, T. F. Mentel, and Y. Rudich (2006), Cloud condensation nuclei properties of model and atmospheric HULIS, Atmos. Chem. Phys., 6 , $2465-2481$.

Dufresne, J.-L., J. Quaas, O. Boucher, S. Denvil, and L. Fairhead (2005), Contrasts in the effects on climate of anthropogenic sulfate aerosols between the 20 th and the 21 st century, Geophys. Res. Lett., 32, L21703, doi:10.1029/2005GL023619.

Engelhart, G. J., A. Asa-Awuku, A. Nenes, and S. N. Pandis (2008), CCN activity and droplet growth kinetics of fresh and aged monoterpene secondary organic aerosol, Atmos. Chem. Phys., 8, 3937-3949.

Feichter, J., E. Roeckner, U. Lohmann, and B. Liepert (2004), Nonlinear aspects of the climate response to greenhouse gas and aerosol forcing, J. Clim., 17, 2384-2398, doi:10.1175/1520-0442(2004)017<2384: NAOTCR $>2.0 . \mathrm{CO} ; 2$.

Forster, P., et al. (2007), Changes in Atmospheric Constituents and in Radiative Forcing, edited by S. Solomon et al., Cambridge Univ. Press, Cambridge, U. K.

Fountoukis, C., and A. Nenes (2005), Continued development of a cloud droplet formation parameterization for global climate models, J. Geophys. Res., 110, D11212, doi:10.1029/2004JD005591.

Fountoukis, C., et al. (2007), Aerosol-cloud drop concentration closure for clouds sampled during ICARTT, J. Geophys. Res., 112, D10S30, doi:10.1029/2006JD007272.

Garrett, T. J., and C. Zhao (2006), Increased Arctic cloud longwave emissivity associated with pollution from mid-latitudes, 440, 787-789, doi:10.1038/nature04636.

Ghan, S., L. Leung, R. Easter, and H. Abdul-Razzak (1997), Prediction of cloud droplet number in a general circulation model, J. Geophys. Res., 102(D18), 21,777-21,794, doi:10.1029/97JD01810.

Giebl, H., A. Berner, G. Reischl, H. Puxbaum, A. Kasper-Giebl, and R. Hitzenberger (2002), CCN activation of oxalic and malonic acid test aerosols with the University of Vienna cloud condensation nuclei counter, Aerosol Sci., 33, 1623-1634, doi:10.1016/S0021-8502(02)00115-5.

Glantz, P., and K. J. Noone (2000), A physically based algorithm for estimating the relationship between aerosol mass and cloud droplet number, Tellus, Ser. B, 52, 1216-1231, doi:10.1034/j.1600-0889.2000.01077.x. 
Griffin, R. J., D. R. Cocker, R. C. Flagan, and J. H. Seinfeld (1999a), Organic aerosol formation from the oxidation of biogenic hydrocarbons, J. Geophys. Res., 104(D3), 3555-3567, doi:10.1029/1998JD100049.

Griffin, R. J., D. R. Cocker, J. H. Seinfeld, and D. Dabdub (1999b), Estimate of global atmospheric organic aerosol from oxidation of biogenic hydrocarbons, Geophys. Res. Lett., 26(17), 2721-2724, doi:10.1029/ 1999GL900476.

Han, Q., W. B. Rossow, and A. A. Lacis (1994), Near-global survey of effective droplet radii using ISCCP data, J. Clim., 7, 465-497, doi:10.1175/1520-0442(1994)007<0465:NGSOED>2.0.CO;2.

Han, Q., W. B. Rossow, J. Chou, and R. M. Welch (1998), Global variation of column droplet concentration in low-level clouds, Geophys. Res. Lett., 25, 1419-1422, doi:10.1029/98GL01095.

Hansen, J., A. Lacis, G. Russel, P. Stone, I. Fung, R. Ruedy, and J. Lerner (1984), Climate sensitivity: Analysis of feedback mechanisms, in Climate Processes and Climate Sensitivity, Geophys. Monogr. Ser, vol. 29, edited by J. Hansen and T. Takahashi, pp. 130-163, AGU, Washington, D. C.

Haywood, J. M., D. L. Roberts, A. Slingo, J. M. Edwards, and K. P. Shine (1997), General circulation model calculations of the direct radiative forcing by anthropogenic sulfate and fossil-fuel soot aerosol, J. Clim., 10, 1562-1577, doi:10.1175/1520-0442(1997)010<1562: GCMCOT $>2.0 . \mathrm{CO} ; 2$.

Held, I. M., and B. J. Soden (2006), Robust responses of the hydrological cycle to global warming, J. Clim., 19(21), 5686-5699, doi:10.1175/ JCLI3990.1.

Hoose, C., U. Lohmann, R. Bennartz, B. Croft, and G. Lesins (2008), Global simulations of aerosol processing in clouds, Atmos. Chem. Phys. Discuss., 8, 13,555-13,618.

Hoose, C., J. E. Kristjansson, T. Iversen, A. Kirkevåg, Ø. Seland, and A. Gettelman (2009), Constraining cloud droplet number concentration in GCMs suppresses the aerosol indirect effect, Geophys. Res. Lett., 36, L12807, doi:10.1029/2009GL038568.

Hsieh, W. C., H. Jonsson, L. P. Wang, G. Buzorius, R. C. Flagan, J. H. Seinfeld, and A. Nenes (2009), On the representation of droplet coalescence and autoconversion: Evaluation using ambient cloud droplet size distributions, J. Geophys. Res., 114, D07201, doi:10.1029/ 2008JD010502.

Jacobson, M. Z. (2000), A physically based treatment of elemental carbon optics: Implication for global direct forcing of aerosols, Geophys. Res. Lett., 27, 217-220, doi:10.1029/1999GL010968.

Jones, P. D., M. New, D. E. Parker, S. Martin, and I. Rigor (1999), Surface air temperature and its variations over the last 150, Rev. Geophys., 37, 173-199, doi:10.1029/1999RG900002.

Khairoutdinov, M., and Y. Kogan (2000), A new cloud physics parameterization in a large-eddy simulation model of marine stratocumulus, Mon. Weather Rev., 128(1), 229-243, doi:10.1175/1520-0493(2000) $128<0229$ :ANCPPI $>2.0$.CO;2.

Kiehl, J. T., and K. Trenberth (1997), Earth's annual global mean energy budget, Bull. Am. Meteorol. Soc., 78, 197-208, doi:10.1175/1520-0477 (1997)078<0197:EAGMEB >2.0.CO;2.

Kirkevåg, A., T. Iversen, J. E. Kristjánsson, Ø. Seland, and J. B. Debernard (2008a), On the additivity of climate response to anthropogenic aerosols and $\mathrm{CO}_{2}$, and the enhancement of future global warming by carbonaceous aerosols, Tellus, Ser. A, 60, 513-527.

Kirkevåg, A., T. Iversen, Ø. Seland, J. Debernard, T. Storelvmo, and J. E. Kristjánsson (2008b), Aerosol cloud-climate interactions in the climate model CAM-Oslo, Tellus, Ser. A, 60, 492-512.

Koch, D., S. Menon, A. D. Genio, R. Ruedy, I. Alienov, and G. A. Schmidt (2009), Distinguishing aerosol impacts on climate over the past century, J. Clim., 22(10), 2569-2677, doi:10.1175/2008JCLI2573.1.

Kristjansson, J. E. (2002), Studies of the aerosol indirect effect from sulfate and black carbon aerosols, J. Geophys. Res., 107(D15), 4246, doi:10.1029/2001JD000887.

Kristjánsson, J. E., T. Iversen, A. Kirkevåg, Ø. Seland, and J. Debernard (2005), Response of the climate system to aerosol direct and indirect forcing: Role of cloud feedbacks, J. Geophys. Res., 110, D24206, doi:10.1029/2005JD006299.

Liao, H., and J. H. Seinfeld (2005), Global impacts of gas-phase chemistryaerosol interactions on direct radiative forcing by anthropogenic aerosols and ozone, J. Geophys. Res., 110, D18208, doi:10.1029/2005JD005907.

Liao, H., P. J. Adams, S. H. Chung, J. H. Seinfeld, L. J. Mickley, and D. J. Jacob (2003), Interactions between tropospheric chemistry and aerosols in a unified general circulation model, J. Geophys. Res., 108(D1), 4001, doi:10.1029/2001JD001260.

Liao, H., J. H. Seinfeld, P. J. Adams, and L. J. Mickley (2004), Global radiative forcing of coupled tropospheric ozone and aerosols in a unified general circulation model, J. Geophys. Res., 109, D16207, doi:10.1029/ 2003JD004456.
Liao, H., W.-T. Chen, and J. H. Seinfeld (2006), Role of climate change in global predictions of future tropospheric ozone and aerosols, J. Geophys. Res., 111, D12304, doi:10.1029/2005JD006852.

Liao, H., Y. Zhang, W.-T. Chen, and J. H. Seinfeld (2009), Effect of chemistry-aerosol-climate coupling on predictions of future climate and future levels of tropospheric ozone and aerosols, J. Geophys. Res., 114, D10306, doi:10.1029/2008JD010984.

Limbeck, A., and H. Puxbaum (2000), Dependence of in-cloud scavenging of polar organic aerosol compounds on the water solubility, J. Geophys Res., 105(D15), 19,857-19,867, doi:10.1029/2000JD900123.

Lohmann, U., and J. Feichter (2005), Global indirect aerosol effects: A review, Atmos. Chem. Phys., 5, 715-737.

Lohmann, U., P. Stier, C. Hoose, S. Ferrachat, S. Kloster, E. Roeckner, and J. Zhang (2007), Cloud microphysics and aerosol indirect effects in the global climate model ECHAM5-HAM, Atmos. Chem. Phys., 7, 3425-3446.

Manabe, S., and R. T. Wetherald (1975), Effects of doubling $\mathrm{CO}_{2}$ concentration on climate of a general circulation model, J. Atmos. Sci., 32, 3-15, doi:10.1175/1520-0469(1975)032<0003:TEODTC >2.0.CO;2.

Martin, G. M., D. W. Johnson, and A. Spice (1994), The measurement and parameterization of effective radius of droplets in warm stratocumulus clouds, J. Atmos. Sci., 51, 1823-1842, doi:10.1175/1520-0469(1994) 051<1823:TMAPOE $>2.0 . \mathrm{CO} ; 2$

Meehl, G. A., et al. (2007), Global Climate Projections, edited by S. Solomon et al., Cambridge Univ. Press, Cambridge, U. K.

Menon, S., A. D. Del Genio, D. Koch, and G. Tselioudis (2002), GCM simulations of the aerosol indirect effect: Sensitivity to cloud parameterization and aerosol burden, J. Atmos. Sci., 59(3), 692-713, doi:10.1175/ 1520-0469(2002)059<0692:GSOTAI $>2.0 . \mathrm{CO} ; 2$.

Meskhidze, N., A. Nenes, W. C. Conant, and J. H. Seinfeld (2005), Evaluation of a new cloud droplet activation parameterization with in situ data from CRYSTAL-FACE and CSTRIPE, J. Geophys. Res., 110, D16202, doi:10.1029/2004JD005703.

Meskhidze, N., R. E. P. Sotiropoulou, A. Nenes, J. Kouatchou, B. Das, and J. M. Rodriguez (2007), Aerosol-cloud interactions in the NASA GMI: Model development and indirect forcing assessments for sulfate aerosol, Atmos. Chem. Phys. Discuss., 7, 14,295-14,330.

Mickley, L. J., D. J. Jacob, B. D. Field, and D. Rind (2004), Climate response to the increase in tropospheric ozone since preindustrial times: A comparison between ozone and equivalent $\mathrm{CO} 2$ forcings, J. Geophys Res., 109, D05106, doi:10.1029/2003JD003653.

Ming, Y., V. Ramaswamy, P. A. Ginoux, L. W. Horowitz, and L. M. Russell (2005), Geophysical Fluid Dynamics Laboratory general circulation model investigation of the indirect radiative effects of anthropogenic sulfate aerosol, J. Geophys. Res., 110, D22206, doi:10.1029/2005JD006161.

Mitas, C. M., and A. Clement (2005), Has the Hadley cell been strengthening in recent decades? Geophys. Res. Lett., 32, L03809, doi:10.1029/ 2004GL021765

Myhre, G., F. Stordal, K. Restad, and I. S. A. Isaksen (1998), Estimation of the direct radiative forcing due to sulfate and soot aerosols, Tellus, Ser. B, $50,463-477$.

Nenes, A., and J. H. Seinfeld (2003), Parameterization of cloud droplet formation in global climate models, J. Geophys. Res., 108(D14), 4415, doi:10.1029/2002JD002911.

Peng, Y., U. Lohmann, and R. Leaitch (2005), Importance of vertical velocity variations in the cloud droplet nucleation process of marine stratus clouds, J. Geophys. Res., 110, D21213, doi:10.1029/2004JD004922.

Penner, J. E., J. Quaas, T. Storelvmo, T. Takemura, O. Boucher, H. Guo, A. Kirkevåg, J. E. Kristjánsson, and Ø. Seland (2006), Model intercomparison of indirect aerosol effects, Atmos. Chem. Phys., 6, 33913405

Pierce, J. R., and P. J. Adams (2006), Global evaluation of CCN formation by direct emission of sea salt and growth of ultrafine sea salt, J. Geophys. Res., 111, D06203, doi:10.1029/2005JD006186.

Quaas, J., and O. Boucher (2005), Constraining the first aerosol indirect radiative forcing in the LMDZ GCM using POLDER and MODIS satellite data, Geophys. Res. Lett., 32, L17814, doi:10.1029/ 2005 GL023850.

Quaas, J., O. Boucher, and F. Breon (2004), Aerosol indirect effects in POLDER satellite data and the Laboratoire de Meteorologie DynamiqueZoom (LMDZ) general circulation model, J. Geophys. Res., 109, D08205, doi:10.1029/2003JD004317.

Quaas, J., O. Boucher, and U. Lohmann (2006), Constraining the total aerosol indirect effect in the LMDZ and ECHAM4 GCMs using MODIS satellite data, Atmos. Chem. Phys., 6, 947-955.

Raymond, T. M., and S. N. Pandis (2002), Cloud activation of singlecomponent organic aerosol particles, J. Geophys. Res., 107(D24), 4787, doi:10.1029/2002JD002159. 
Rayner, N. A., D. E. Parker, E. B. Horton, C. K. Folland, L. V. Alexander, D. P. Rowell, E. C. Kent, and A. Kaplan (2003), Global analyses of SST, sea ice and night marine air temperature since the late nineteenth century, J. Geophys. Res., 108(D14), 4407, doi:10.1029/2002JD002670.

Rind, D., J. Lerner, J. Jonas, and C. McLinden (2007), Effects of resolution and model physics on tracer transports in the NASA Goddard Institute for Space Studies general circulation models, J. Geophys. Res., 112, D09315, doi:10.1029/2006JD007476.

Rotstayn, L. D., and U. Lohmann (2002), Tropical rainfall trends and the indirect aerosol effect, J. Clim., 15(15), 2103-2116, doi:10.1175/15200442(2002)015<2103:TRTATI>2.0.CO;2.

Rotstayn, L. D., B. F. Ryan, and J. E. Penner (2000), Precipitation changes in a GCM resulting from the indirect effects of anthropogenic aerosols, Geophys. Res. Lett., 27(19), 3045-3048, doi:10.1029/2000GL011737.

Russell, G. L., J. R. Miller, and L. C. Tsang (1985), Seasonal oceanic heat transports computed from an atmospheric model, Dyn. Atmos. Oceans, 9(3), 253-271, doi:10.1016/0377-0265(85)90022-3.

Schmidt, G. A., et al. (2006), Present-day atmospheric simulations using GISS ModelE: Comparison to in situ, satellite, and reanalysis data, J. Clim., 19(2), 153-192, doi:10.1175/JCLI3612.1.

Seinfeld, J. H., and S. N. Pandis (1998), Atmospheric Chemistry and Physics: From Air Pollution to Climate Change, John Wiley, New York. Stephens, G. L., et al. (2008), CloudSat mission: Performance and early science after the first year of operation, J. Geophys. Res., 113, D00A18, doi:10.1029/2008JD009982.

Sun, J., and P. A. Ariya (2006), Atmospheric organic and bio-aerosols as cloud condensation nuclei (CCN): A review, Atmos. Environ., 40(5), 795-820, doi:10.1016/j.atmosenv.2005.05.052.

Sundqvist, H., E. Berge, and J. E. Kristjansson (1989), Condensation and cloud parameterization studies with a mesoscale numerical weather prediction model, Mon. Weather Rev., 117, 1641-1657, doi:10.1175/15200493(1989)117<1641:CACPSW>2.0.CO;2.
Takemura, T., T. Nozawa, S. Emori, T. Y. Nakajima, and T. Nakajima (2005), Simulation of climate response to aerosol direct and indirect effects with aerosol transport-radiation model, J. Geophys. Res., 110, D02202, doi:10.1029/2004JD005029.

Toon, O. B., J. B. Pollack, and B. N. Khare (1976), Optical-constants of several atmospheric aerosol species: Ammonium-sulfate, aluminumoxide, and sodium-chloride, J. Geophys. Res., 81(33), 5733-5748, doi:10.1029/JC081i033p05733.

Williams, K. D., A. Jones, D. L. Roberts, C. A. Senior, and M. J. Woodage (2001), The response of the climate system to the indirect effects of anthropogenic sulfate aerosol, Clim. Dyn., 17(11), 845-856, doi:10.1007/ s003820100150.

Zwiers, F. W., and H. von Storch (1995), Taking serial-correlation into account in tests of the mean, J. Clim., 8(2), 336-351, doi:10.1175/ 1520-0442(1995)008<0336:TSCIAI $>2.0 . \mathrm{CO} ; 2$.

P. J. Adams, Departments of Civil and Environmental Engineering and Engineering and Public Policy, Carnegie Mellon University, Pittsburgh, PA 15213, USA. (petera@andrew.cmu.edu)

W.-T. Chen and J.-L. F. Li, Jet Propulsion Laboratory, California Institute of Technology, MS 183-501, 4800 Oak Grove Dr., Pasadena, CA 91109, USA. (annechen@caltech.edu; jli@jpl.nasa.gov)

H. Liao, LAPC, Institute of Atmospheric Physics, Chinese Academy of Sciences, Beijing, 100029, China. (hongliao@mail.iap.ac.cn)

A. Nenes, Schools of Earth and Atmospheric Sciences and Chemical and Biomolecular Engineering, Georgia Institute of Technology, Atlanta, GA 30332, USA. (athanasios.nenes@gatech.edu)

J. H. Seinfeld, Departments of Environmental Science and Engineering and Chemical Engineering, California Institute of Technology, Mail Code 210-41,Pasadena, CA 91125, USA. (seinfeld@caltech.edu) 